\title{
Research on the Attenuation Characteristics of AE Signals of Marble and Granite Stone
}

\author{
Haiyan Wang, ${ }^{1,2}$ Ji Ma $\mathbb{D}^{3},{ }^{3}$ Feng Du $\mathbb{D}^{4,5}$ Gongda Wang $\mathbb{D}^{2},{ }^{2}$ Quan Zhang, ${ }^{6}$ and Xiaoshen $\mathrm{Li}^{6}$ \\ ${ }^{1}$ China Coal Research Institute, Beijing 100013, China \\ ${ }^{2}$ State Key Laboratory of the Ministry of Education of China for High-efficient Mining and Safety of Metal Mines, \\ University of Science and Technology Beijing, Beijing 100083, China \\ ${ }^{3}$ School of Safety Science and Engineering, Henan Polytechnic University, Jiaozuo, Henan 454000, China \\ ${ }^{4}$ Beijing Key Laboratory for Precise Mining of Intergrown Energy and Resources, \\ China University of Mining \& Technology (Beijing), Beijing 100083, China \\ ${ }^{5}$ State Key Laboratory Cultivation Base for Gas Geology and Gas Control, Henan Polytechnic University, Jiaozuo 454000, China \\ ${ }^{6}$ Tingnan Coal Industry Co., Ltd., Taiyuan, Shanxi 713600, China \\ Correspondence should be addressed to Ji Ma; jmacumtb@126.com and Feng Du; fengducumtb@126.com
}

Received 29 October 2020; Revised 19 November 2020; Accepted 14 December 2020; Published 24 December 2020

Academic Editor: Chun Zhu

Copyright (C) 2020 Haiyan Wang et al. This is an open access article distributed under the Creative Commons Attribution License, which permits unrestricted use, distribution, and reproduction in any medium, provided the original work is properly cited.

\begin{abstract}
When an underground rock is deformed or fractured by an external or internal force, the energy will be released in the form of an elastic wave, which is known as the acoustic emission (AE) phenomenon. Extracting useful information from complex AE signals for the early warning of fracture characteristics and the damage monitoring of rock materials is of great significance for the prevention and control of dynamic disasters in coal mines. In this work, by taking rod-shaped rocks and plate-shaped rocks with different lithologies as the research objects, the elastic wave propagation characteristics of the rod-shaped rocks and plate-shaped rocks were studied by a self-constructed experimental platform. The results demonstrate that the elastic wave attenuation of the rod-shaped marble was the fastest, and the elastic wave attenuation characteristics of the three groups of rod-shaped granite were similar. The attenuation of the $\mathrm{P}$-wave preceded that of the S-wave. With the increase in the propagation distance, the amplitude of the large-scale plate-shaped rock showed an approximate exponential attenuation characteristic. The elastic wave attenuation of the plate-shaped granite in the $0^{\circ}$ direction was stronger than that of the plate-shaped marble, and it was weaker than that of the plate-shaped marble in the $45^{\circ}$ and $90^{\circ}$ directions. The energy changes in marble were more severe than those in granite. The main dominant energy of the AE signals of experimental rock was concentrated in the range of $0-176.78 \mathrm{kHz}$, and part of the residual energy was located in the high-frequency band of $282.25-352.56 \mathrm{kHz}$.
\end{abstract}

\section{Introduction}

Coal resource is an important strategic resource [1-3]. Before the excavation of underground rock mass in coal mines, the original rock stress is in an equilibrium state. The original state of stress balance is destroyed because of the influence of mining activities, resulting in the redistribution of the rock stress and causing fracture damage to the rock mass [4-7]. The changes in the stress state and internal structure often lead to the instability and fracturing of the rock mass, resulting in rockbursts, mine earthquakes, and other coal rock dynamic disasters [8-13]. The process of instability and fracturing of the rock mass is the process of initiation, propagation, and aggregation of internal microcracks, resulting in the formation of macrocracks and the loss of bearing capacity. During this process, the acoustic emission (AE) instrument can detect a large number of $\mathrm{AE}$ signals [14-26]. Nowadays, AE technology can be used for the dynamic and real-time monitoring of $\mathrm{AE}$ signals in the process of rock failure, as well as the timely analysis of the changing characteristics of AE signals. Not only that, but it helps explore rock stability and predict the development and fracture degree of rock internal cracks, which has become an effective early warning and prevention means for coal rock 
dynamic disasters [17-21]. Each AE signal contains a wealth of information concerning changes in the internal structure of the rock mass. Understanding how to extract useful information from complex AE signals for the early warning of fracture characteristics and the damage monitoring of rock masses is still an urgent problem that needs to be solved.

To date, several studies focusing on the application of $\mathrm{AE}$ technology on rock damage monitoring and the AE signal processing of rock failure have been conducted. Through repeated load stress experiments, Goodman and Richard [22] presented that the AE of rock can be divided into three types: the first type only appears under low stress, and it will not exist under the second load; the second type appears under low stress, and it will still exist under the second load; and the third type only appears under high stress, confirming that the rock also has a Kaiser effect. It lays a foundation for the development of AE technology in the field of rock mechanics. Cai et al. $[15,23]$ and Saltas et al. $[24,25]$ systematically investigated the deformation and failure mechanisms of rocks using AEs. Qi [26] introduced the research of wavelet signal processing technology in the fracture behavior of composite materials. Manthei et al. [27] analyzed the dispersion characteristics of $\mathrm{AE}$ signals in the plate structure using the wavelet transform method. They found the time when the wave arrived at the sensor and determined an accurate location of the AE source. Jeong and Jang [28] examined the failure mechanisms in rocks through moment tensor methods applied to AE events. Chang and Lee [29] applied the tensor analysis of the AE to evaluate the cracks and damage of rocks under triaxial compression. In addition, some scholars studied the AE spatial location in coal rock instability engineering $[15,30-34]$. However, few analyses have compared and studied the similarities and differences of the elastic wave propagation characteristics in different rock materials by comprehensively using the methods of signal analysis and wavelet packet waveform analysis. In these analyses, the AE signal waveform is analyzed, and the time-frequency characteristics of the $\mathrm{AE}$ signal waveform received by different position sensors were extracted.

Therefore, in this work, the rod-shaped and plate-shaped rock materials with different lithologies were selected, and the elastic wave propagation characteristic experimental platform was constructed. The propagation characteristics of the elastic wave in the rod-shaped rock materials of the same lithology with different AE sources were studied. Furthermore, the propagation characteristics of the elastic wave in the rod-shaped rock materials with different lithologies were compared. The general laws of waveform attenuation and distance satisfaction of the thin plate-shaped rock materials were summarized. In general, the rock materials of different lithologies and those with the same lithology but from different regions were selected. The laws of elastic wave and energy in the time and frequency domains of these rocks under one-dimensional rod-shaped and two-dimensional plate-shaped conditions were compared and analyzed. Through this research, certain research methods are presented, and a theoretical basis for the study of wave propagation law in complex three-dimensional rock is provided.

\section{Experiments}

2.1. Preparation of Test Samples. Considering the mineralogical and petrological characteristics of facing stones, the experimental rocks mainly consisted of marble and granite, which included 5 groups of rod-shaped rocks and 2 groups of plate-shaped rocks. For the rod-shaped rocks, three groups were granite, and two groups were marble. For the plate-shaped rocks, one group was granite, and the other was marble. According to the unified number of natural stone in China [35], the numbers of these 7 groups of experimental rocks are G3768, G3561, TBG, AAM, GAM, G3761-L, and GAM-L, respectively. The specific names, types, and sizes of these various rocks are presented in Table 1.

2.2. Experimental Scheme. In accordance with the purpose of this experimental work, two kinds of experimental platforms for $\mathrm{AE}$ wave propagation characteristics were correspondingly designed for the rod-shaped and plateshaped rocks.

2.2.1. Experiment of Elastic Wave Propagation Characteristics of Rod-Shaped Rock. When the length of the detected object is much larger than its width, the object can be regarded as a rod. As shown in Table 1, the first five samples are rod-shaped rocks. A rod-shaped rock was horizontally fixed on the self-made fixture, with $6 \mathrm{AE}$ sensors arranged on its upper surface. As for the GAM sample with a length of $1 \mathrm{~m}, 5$ sensors were arranged on its upper surface, as shown in Figure 1. To make the sensor better receive the AE signal, Vaseline was used as the coupling agent between the sensor and the rod-shaped rock, and the sensor was fixed with insulating electrical tape. The position coordinates of each sensor are shown in Table 2. To simulate the generation of the $\mathrm{S}$-wave and $\mathrm{P}$-wave and analyze their propagation characteristics in different stone materials, the signal source points were arranged on the top surface of the right end and the vertical surface of the end of the rod-shaped rock. The pulse excitation source was used as the known AE source. It should be noted that the $\mathrm{P}$-wave is excited by terminal pulse excitation, and the $S$-wave is excited by end pulse excitation.

2.2.2. Experiment of Elastic Wave Propagation Characteristics of Plate-Shaped Rock. The AE receiving signal sensor was fixed on the upper surface of the GAM-L sample $(89,30)$ and the G3761-L sample $(111,20.5)$. The point was then marked every $5 \mathrm{~cm}$ from the sensor in three directions of $0^{\circ}$, $90^{\circ}$, and $45^{\circ}$ on the surface of the samples to lay the excitation pulse signal source, as exhibited in Figure 2.

\subsection{Experimental System}

2.3.1. Composition of Experimental System. The experimental system was mainly composed of the DS5 series AE data acquisition system, adjustable excitation pulse source gain amplifier, and DS5 series AE signal acquisition and analysis software, as shown in Figure 3. Among them, the AE 
TABLE 1: Parameters of the rod-shaped and plate-shaped rock samples.

\begin{tabular}{lccr}
\hline Scientific name & Number & Type & $\begin{array}{c}\text { Size } / \text { mm } \\
\text { Length } \times \text { width } \times \text { thickness }\end{array}$ \\
\hline Wu Lianhong & G3768 & Granite & $1440 \times 38 \times 15$ \\
Ma Hui stone & G3561 & Granite & $2150 \times 40 \times 20$ \\
Tan Brown & TBG & Granite & $1400 \times 60 \times 16$ \\
Ariston & GAM & Artificial marble & $1500 \times 59 \times 12$ \\
Giallo Atlantide & GAM & Marble & $1000 \times 30 \times 18$ \\
Wu Lianhong lamel & GAM-L & Granite & $2220 \times 620 \times 12$ \\
Giallo Atlantide lamel & Marble & $1780 \times 760 \times 15$ \\
\hline
\end{tabular}

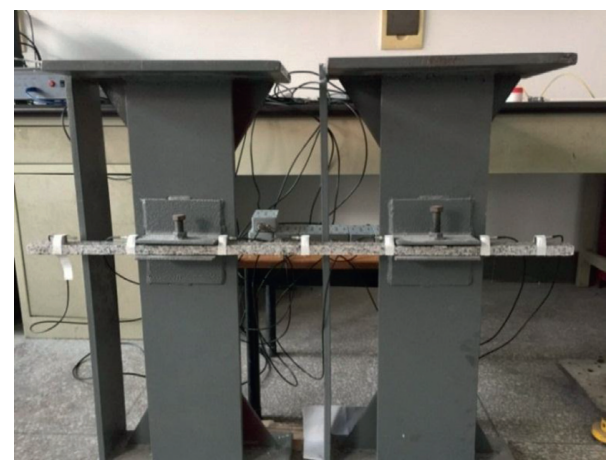

Figure 1: The sensors network layout for the rod-shaped rock samples.

TABLE 2: The coordinates of sensors on the rod-shaped rock samples.

\begin{tabular}{lcccccc}
\hline \multirow{2}{*}{ Number of rocks } & \multicolumn{4}{c}{ Number of sensors } \\
& S1 & S2 & S3 & S4 & S5 & 100 \\
\hline G3768 & 5 & 20 & 50 & 70 & 135 \\
G3561 & 5 & 20 & 50 & 70 & 100 & 135 \\
TBG & 5 & 20 & 50 & 70 & 100 & 100 \\
AAM & 5 & 20 & 50 & 70 & 135 \\
GAM & 5 & 20 & 50 & - \\
\hline
\end{tabular}

The location of each sensor is the distance from the right end of the fixed bar, $\mathrm{cm}$.

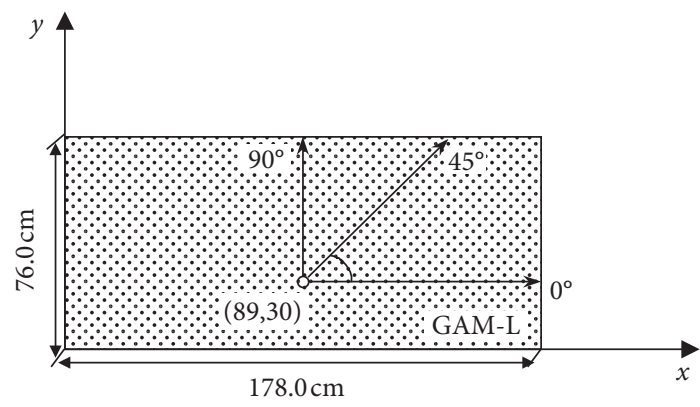

(a)

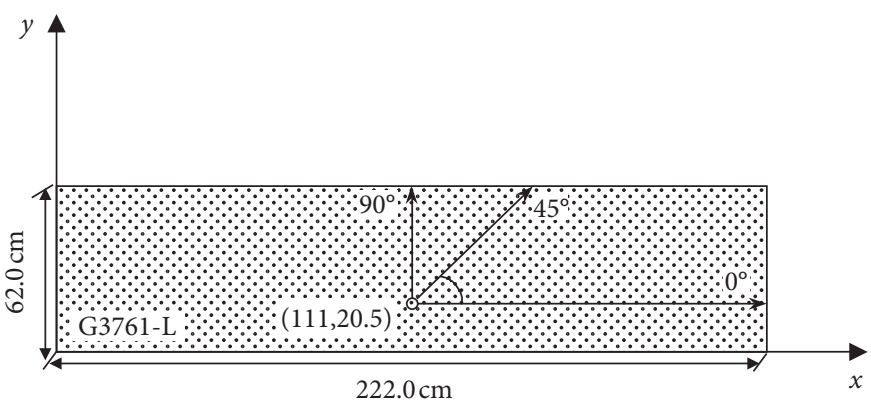

(b)

Figure 2: The diagram of sensor placement plate-shaped rock. (a) GAM-L. (b) G3761-L.

data acquisition system mainly included the DS5-8B AE analyzer, RS-2A AE sensor, adjustable gain amplifier, excitation pulse source signal gain amplifier, relevant data acquisition, processing software, and computer. As the peak frequency of the RS-2A AE sensor was $150 \mathrm{kHz}$, it can receive an AE signal in the range of $60-400 \mathrm{kHz}$. To meet the accuracy of experimental data acquisition, the sampling frequency was set to $3 \mathrm{MHz}$. 


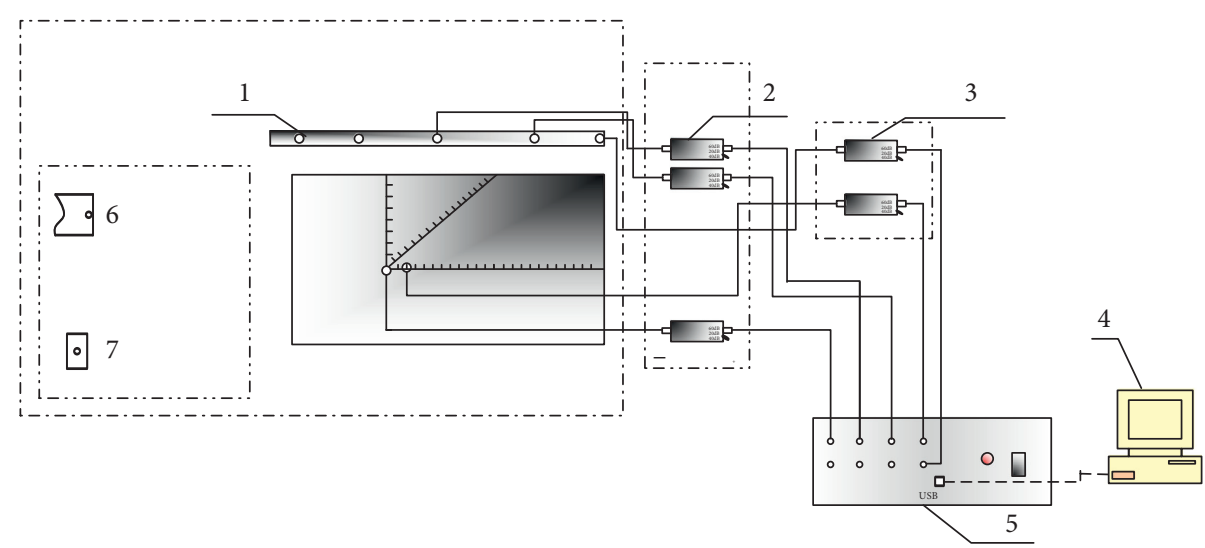

Figure 3: Experimental system. 1: RS-2A sensor; 2: adjustable gain amplifier; 3: adjustable gain amplifier of excitation pulse source; 4: computer; 5: acoustic emission analyzer; 6: top view of the position of the end face excitation pulse signal; 7: profile of the position of terminal excitation pulse signal.

\subsubsection{Setting of Acoustic Emission Detection Parameters.} Before the experiment, it is necessary to reasonably set the relevant parameters of the $\mathrm{AE}$ instrument-including the detection threshold, timing parameters, and wave speed-to truly reflect the characteristics of the AE source. It should be noted that the propagation speed of the wave is the material property related to the elastic modulus and density of the medium, which is the inherent property of the material. Generally, the wave velocity is mainly used for the location calculation of the AE source, and its uncertainty becomes the main factor affecting the source location. In the process of actual source location, the experimental measurement of wave velocity is needed first. However, the experiments of this work focus on collecting the characteristic parameters and waveform information of the AE signal to study the propagation characteristics of the elastic wave, which does not involve the location of the $\mathrm{AE}$ source. Therefore, the experimental acquisition of wave velocity is not the focus of this work, as it does not affect the acquisition of the research objectives of this paper.

\section{(1) Detection threshold setting}

The indoor environment of this experiment was relatively quiet. Under the general rules of different threshold settings and applicable scope, the threshold value of the experimental system should be carried out at a medium sensitivity of 35-55 dB. After the connection of the experimental system, the $\mathrm{AE}$ data acquisition and processing system are activated, and the entire channel is set at $50 \mathrm{mV}$. At this time, the threshold value is about $40 \mathrm{~dB}$ based on unit conversion, meeting the experimental requirement.

\section{(2) Timing parameter setting}

In this experiment, lead breaking was used to simulate the AE source. Combined with the recommended values of metal materials and composite materials summarized in relevant literature [36], the optimal timing parameters are determined, including peak definition time (PDT), hit definition time (HDT), and hit locking time (HLT). The timing parameters are shown in Table 3.

\section{Analysis of Experimental Results of Elastic Wave Propagation Characteristics}

Through the implementation of the above experimental scheme and the reasonable setting of relevant parameters of the $\mathrm{AE}$ acquisition instrument, effective AE signals of the elastic waves in the propagation process were obtained. The characteristics and parameters of the $\mathrm{AE}$ signals and the waveforms of the AE signals were processed and analyzed, and the discussion was carried out. The specific experimental results and analysis are as follows.

\subsection{Analysis of Characteristic Parameters of Acoustic Emission Signals}

3.1.1. Characteristic Parameter Analysis of Rod-Shaped Rock. Amplitude, frequency, and duration are the three elements that could be used to describe microvibration or microfracture. By analyzing the amplitude changes of the monitoring points at different positions, the elastic wave intensity change trend in the rod can be determined. The frequency information at the monitoring points can be used to identify the area, where the AE events are concentrated. The types of AE signals can be clearly identified based on the duration waveform changes. Two characteristic parameters of energy count and amplitude are used to analyze the propagation characteristics of elastic waves of different rod-shaped rocks. According to the definition of energy count, since the acquisition system obtains discrete point data, the energy of the AE signal is expressed as

$$
E=\sum_{i=1}^{N} V(i)^{2},
$$

where $N$ is the number of discrete points of the AE signals, and $V(i)$ represents the amplitude of the signal discrete points. The amplitude usually reflects the magnitude of the event [28], and the attenuation characteristics of the AE signal waveform can be explored through the change in amplitude. 
TABLE 3: Timing parameters in the experiment.

\begin{tabular}{|c|c|c|c|c|c|c|c|}
\hline Timing parameter & G3768 & G3561 & TBG & AAM & GAM & G3761-L & $\overline{\text { GAM-L }}$ \\
\hline $\mathrm{PDT} / \mu \mathrm{s}$ & 100 & 150 & 150 & 150 & 150 & 100 & 100 \\
\hline $\mathrm{HDT} / \mu \mathrm{s}$ & 200 & 300 & 300 & 300 & 300 & 200 & 200 \\
\hline $\mathrm{HLT} / \mu \mathrm{s}$ & 300 & 500 & 500 & 500 & 500 & 300 & 300 \\
\hline
\end{tabular}

Assuming that the AE signal is monitored at a distance of $5 \mathrm{~cm}$ from the pulse excitation source as the reference, the amplitude relative attenuation rate and energy relative attenuation rate of the elastic wave passing through the rob can be expressed as

$$
\begin{aligned}
& \Delta A_{j}=20 \lg \frac{A_{j}}{A_{s 1}}, \\
& \Delta E_{j}=20 \lg \frac{E_{j}}{E_{s 1}},
\end{aligned}
$$

where $A_{s 1}$ and $E_{s 1}$ represent the amplitude and energy parameters measured at point $s 1(j=s 2, s 3, s 4, s 5, s 6)$.

Taking the existence of error factors into consideration, pulse vibration was carried out four times for each group of rock, and the average value of the results was taken for discussion. The curves of the energy and amplitude distance relative attenuation rate for each group of rocks are shown in Figure 4.

It can be seen from Figure 4 that the characteristic parameters of amplitude and energy in the rod-shaped rocks show the characteristics of gradual attenuation with the increase of distance. Compared with the characteristic parameter values collected at the $5 \mathrm{~cm}$ measuring point, the relative attenuation rate of amplitude is greater than that of energy. It shows that the amplitude directly reflects the intensity of the $\mathrm{AE}$ events at different measuring points. However, the energy only reflects the relative intensity of events, which is affected by factors such as threshold value and working frequency, and the relative attenuation rate with distance cannot show the energy change characteristics of the AE signals. The relative attenuation rate of the $\mathrm{S}$-wave generated by the source signal excited by the pulse on the end surface of each group of rocks is lower than that of the pulse compression wave at the terminal area, indicating that the $\mathrm{P}$-wave came before the $\mathrm{S}$-wave in the process of linear elastic wave propagation and changed violently.

The mutation points of the relative amplitude attenuation rate both appear at the measuring point of $100 \mathrm{~cm}$ for G3768, G3561, and TBG, because the length of G3768 and TBG is close to their amplitudes. Furthermore, the relative attenuation rate tends to be stable after $100 \mathrm{~cm}$. The abnormal phenomenon appears after $100 \mathrm{~cm}$, because the $\mathrm{AE}$ signal produced by the excitation pulse in the terminal area of TBG suddenly increases. It shows that, even if the rock with the same lithology is limited by its complex composition, anisotropy, and size, the $\mathrm{AE}$ wave propagation does not decay exponentially but exhibits a sudden attenuation characteristic. Moreover, because of the fast propagation speed of the P-wave, the reflection of the rock boundary on the original AE signal is superimposed on the original signal, and the frequency dispersion of the original signal increases with the increase of the propagation distance. As a result, the signal after $100 \mathrm{~cm}$ in TBG is a mixed distortion signal. The length of G3561 is $2150 \mathrm{~cm}$, and its relative attenuation rate of energy and amplitude exhibited decreasing trends. The relative attenuation rates of energy at the $70 \mathrm{~cm}$ measuring point were abnormal, which were, respectively, $1.5 \mathrm{~dB}$ and $0.9 \mathrm{~dB}$ compared with those at the $5 \mathrm{~cm}$ measuring point. The relative attenuation rates of energy at the previous $50 \mathrm{~cm}$ measuring point were $1.3 \mathrm{~dB}$ and $1.1 \mathrm{~dB}$, respectively. The attenuation in this section was relatively weak, which may be caused by the gap in the transverse boundary of this rodshaped rock. The abnormal superposition of the boundary wave on the original wave enhanced the original AE signal.

For different groups of rocks with different lithologies, the relative attenuation rates of the amplitude and energy of AAM presented a relatively flat attenuation trend, and slightly strengthened from the position of the $100 \mathrm{~cm}$ abrupt point to the end of the rod. This indicates that the attenuation characteristics of elastic wave propagation were clear without abnormal mutation even though the composition of the artificial stone is complicated. This is because vacuum pressure technology was used to press the binder and various sizes of crushed stone under vacuum vibration and pressure. It was then made by cutting and grinding. Therefore, its ductility and compactness were good. For marble material GAM with a size of only $100 \mathrm{~cm}$, the relative attenuation rates of the amplitude of the end and terminal pulse excitation at $50 \mathrm{~cm}$ were $3.73 \mathrm{~dB}$ and $3.66 \mathrm{~dB}$, respectively. For G3768, these two values at $70 \mathrm{~cm}$ were $1.93 \mathrm{~dB}$ and $2.23 \mathrm{~dB}$, respectively. For the other four rock samples, these two values at $70 \mathrm{~cm}$ were as follows: $1.79 \mathrm{~dB}$ and $1.77 \mathrm{~dB}$ for G3561, $2.32 \mathrm{~dB}$ and $2.61 \mathrm{~dB}$ for TBG, and $2.56 \mathrm{~dB}$ and $2.71 \mathrm{~dB}$ for AAM. It can be seen that the elastic wave attenuation was the fastest in the marble, and the elastic wave attenuation of the three types of granite was similar. Among them, the TBG had the fastest elastic wave attenuation. In general, the attenuation of the $\mathrm{P}$-wave came before the S-wave.

3.1.2. Characteristic Parameter Analysis of Rod-Shaped Rock. According to the experimental schemes of the G3761-L and GAM-L samples, the elastic wave propagation characteristics in the thin plate-shaped rock were discussed by analyzing the changes in the amplitude of the AE signals. Considering the error factor, pulse vibration was carried out four times for each group of rod-shaped rocks, where the average value of the results was taken for discussion. The attenuation curves of the amplitude of each measuring point in different directions and different lithological samples are presented in Figure 5. 

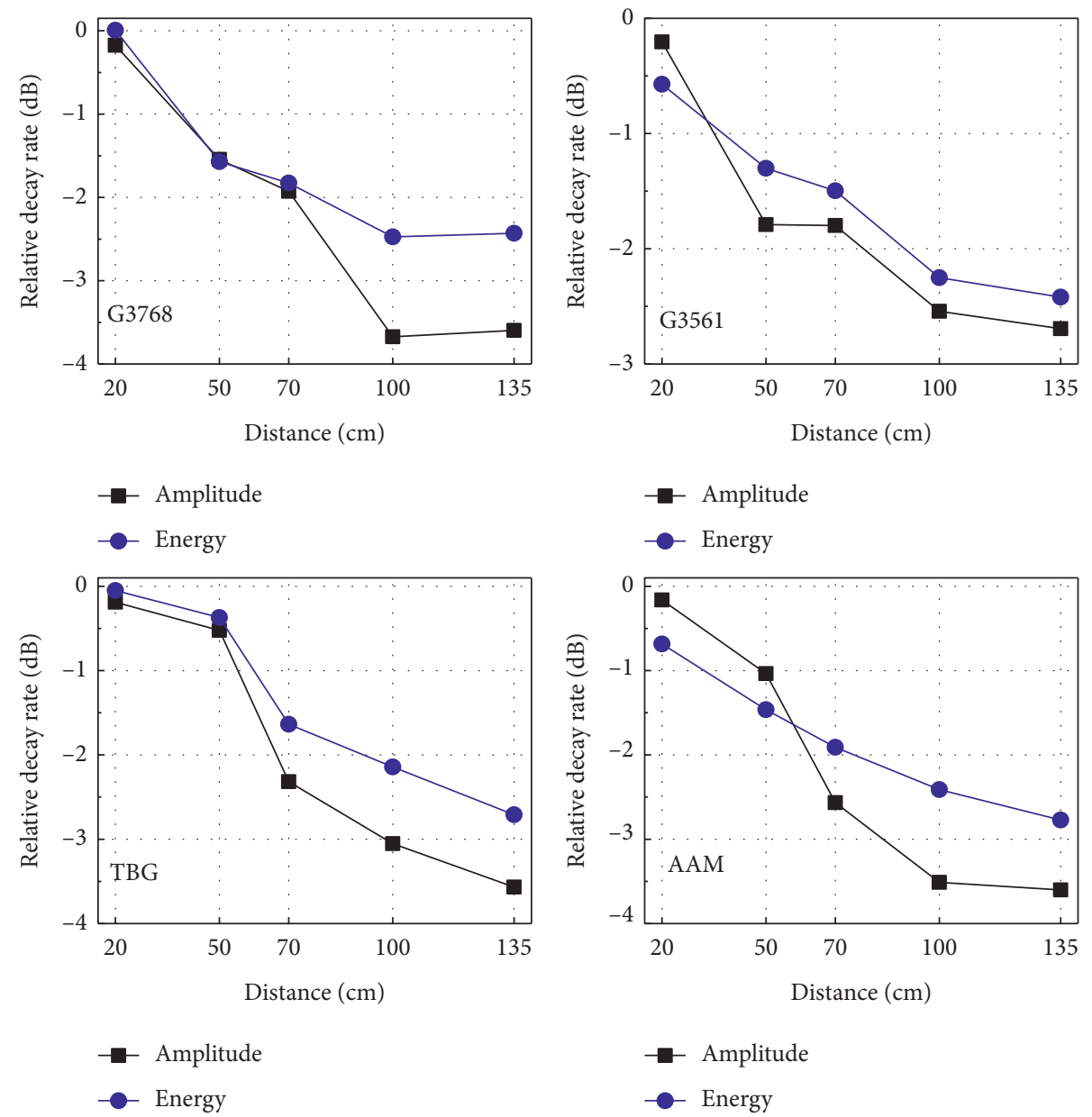

- Amplitude

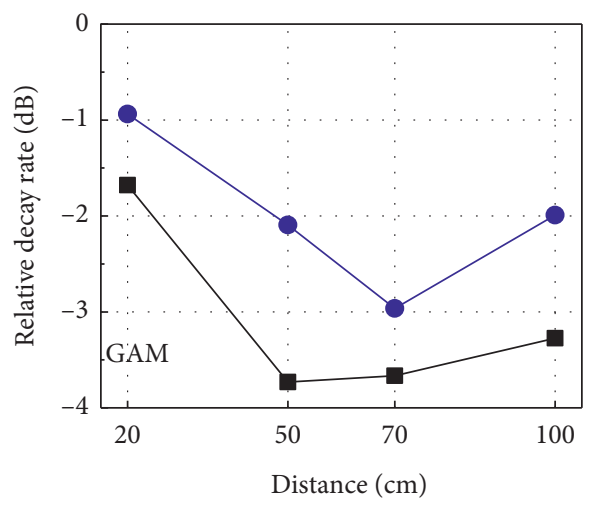

- Amplitude

- Energy

(a)

Figure 4: Continued. 

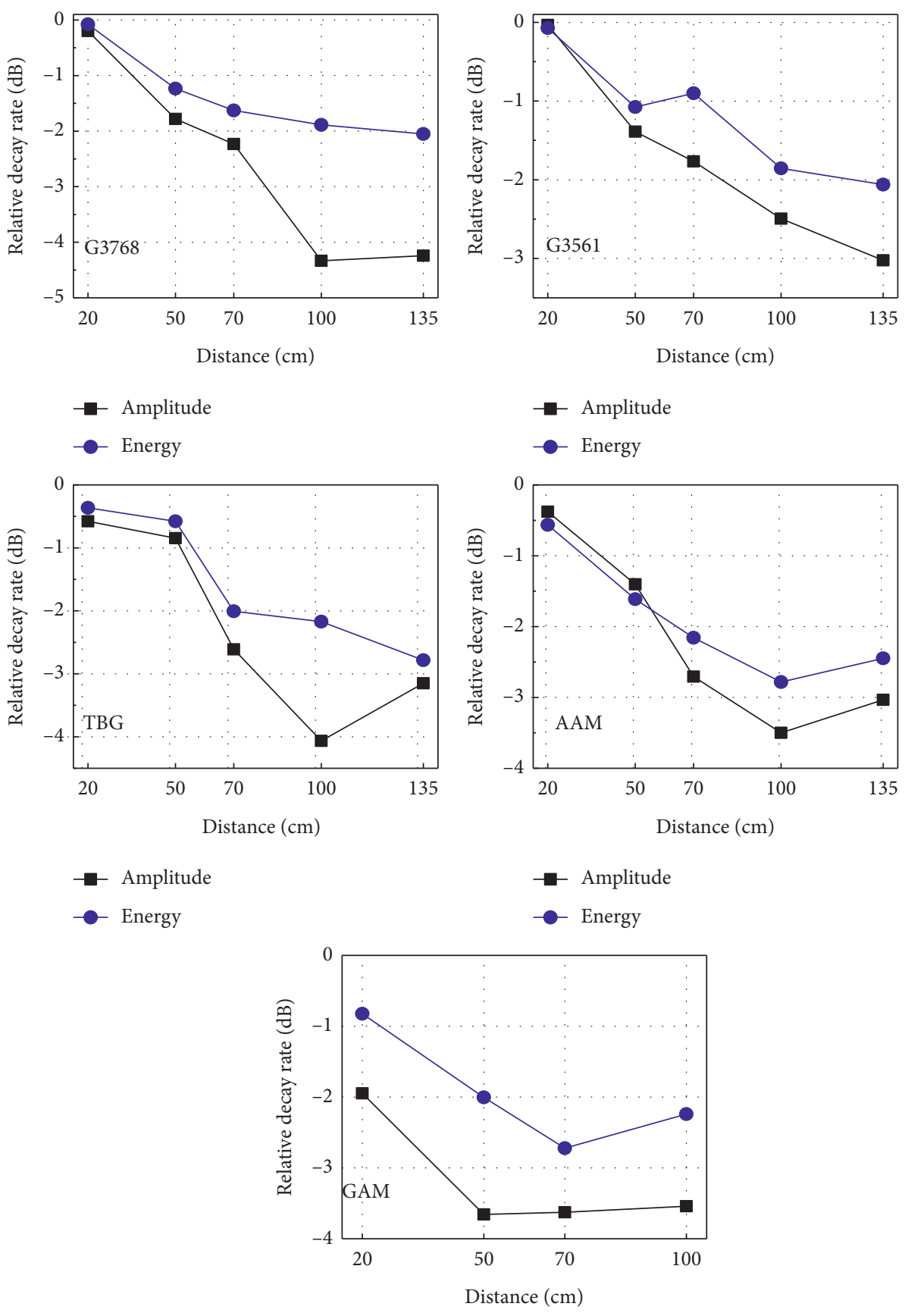

Amplitude

Energy

(b)

Figure 4: The attenuation rates of energy/amplitude with distance. (a) End-pulse excitation (S-wave). (b) Terminal pulse excitation (Pwave).

It can be seen from Figure 5 that the amplitude of the large-scale plane plate rock showed similar exponential attenuation characteristics with the increase of the propagation distance. The $\mathrm{AE}$ wave attenuation of granite was stronger than that of marble in the direction of $0^{\circ}$ and was weaker than that of marble in the directions of $90^{\circ}$ and $45^{\circ}$.
Specifically, due to the diversity and anisotropy of rock components, the attenuation of the $\mathrm{AE}$ wave in the range of $20-80 \mathrm{~cm}$ in the direction of $0^{\circ}$ showed the fluctuation of amplitude between 72 and $83 \mathrm{~dB}$ in both kinds of rock, though the overall trend was declining. The amplitude characteristic parameters extracted from each measuring 

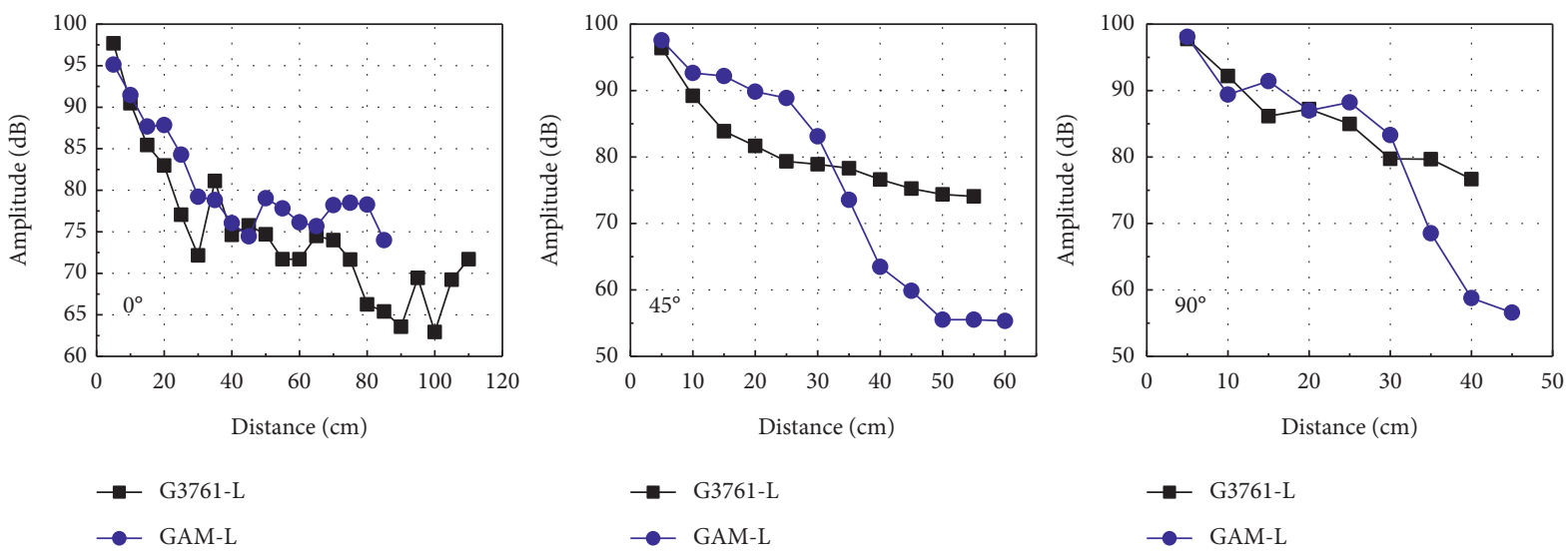

Figure 5: The attenuation curves of the amplitude in different directions for G3761-L and GAM-L.

point arranged in the front and back of the marble in the $45^{\circ}$ direction and $90^{\circ}$ direction presented significant changes. A sudden decrease of amplitude appeared at 30-40 cm, with a decrease of $19.65 \mathrm{~dB}$ in the $45^{\circ}$ direction and $24.55 \mathrm{~dB}$ in the $90^{\circ}$ direction. The amplitude attenuation of granite tended to be stable.

The attenuation curves of the AE energy in different directions for G3761-L and GAM-L are shown in Figure 6. It can be seen that the energy in the marble changes violently, and the energy value in the range of $45-55 \mathrm{~cm}$ in the direction of $0^{\circ}$ exhibits the abnormal phenomenon of step. The energy attenuation was lower than that of the granite stone, which shows the same trend with the amplitude attenuation. The energy value of granite from $45 \mathrm{~cm}$ back to the end of the thin plate is almost maintained at $20-50 \mathrm{mV}$ ms and tends to be stable. In the $45^{\circ}$ direction, the marble exhibited the enhancement of energy value after $55 \mathrm{~cm}$. It is the reflection of the AE wave along the $45^{\circ}$ direction when it met the boundary, and the wave enhancement phenomenon was formed by the superposition of multiple reflections and refractions. The marble and granite showed the same trend in the $90^{\circ}$ direction.

\subsection{Waveform Analysis of Acoustic Emission Signal}

3.2.1. Time Domain Waveform and Spectrum Analysis of Acoustic Emission Original Signal. According to a large number of AE signal waveforms obtained by pulse excitation on the surface of each group of samples, the AE signal waveforms of rod-shaped and plate-shaped rocks were selected from the closest measuring point to the pulse source. The middle measuring point in their respective directions and the end measuring points were analyzed. The specific layout of measuring points is presented in Table 4 .

Since the original statistics of the nonstationary AE signal is a time-varying function, FFT transform was used to analyze the spectral characteristics of the time-domain signal to better understand the variation law of elastic wave in the propagation process. Figure 7 presents the original signal time-domain waveforms of measuring point M2 of each group of rod-shaped rocks, and the corresponding frequency spectrum is shown in Figure 8. The related curves of the AE signal excited from measuring points M2 on the surface of the plate-shaped rocks in the three directions of $0^{\circ}, 90^{\circ}$, and $45^{\circ}$ are shown in Figure 9.

It can be seen from the time-domain diagram that the waveforms of the AE signal generated by pulse excitation were very similar, and the duration was short. For the rodshaped rocks, the durations for granites G3768, G3561, and TBG were in the range of $0.25-1.5 \mathrm{~ms}$, where the waveforms decayed quickly, and the coda waves were not developed. The durations for AAM and GAM were in the range of $0.5-2.0 \mathrm{~ms}$ and $0.5-1.0 \mathrm{~ms}$, respectively. For the plate-shaped rocks, the duration of G3761-L was $0.5-1.5 \mathrm{~ms}$ in the $0^{\circ}$ direction. The duration for GAM-L was $0.25-1.5 \mathrm{~ms}$, and the amplitude attenuation variation was small. Similarly, in the $45^{\circ}$ direction and $90^{\circ}$ direction, the G3761-1 granite showed a shorter duration of time than the GAM-L marble, demonstrating that the homogeneity of the natural granite plateshaped rock is better.

It can be seen from the spectrum that the frequency of the AE signal generated by pulse excitation was relatively high, and the frequency band was relatively narrow. The main frequency domain of each group of rod-shaped rocks was $0-250 \mathrm{kHz}$, and the frequency domain of the AE signal at the M2 position measuring point in each direction of the plate-shaped rocks was $0-300 \mathrm{kHz}$. In this frequency domain, each group of samples with different lithologies shows multiple peaks of frequency, indicating that the waveform of the AE signal is very complex and is a mixture of waves with different characteristics.

\subsubsection{Wavelet Packet Energy Analysis of Acoustic Emission} Signal. According to previous research, wavelet transform only decomposes the low-frequency part-but not the highfrequency part of the original signal. The time-frequency localization could be better analyzed through the introduction of wavelet packet transform, in which the highfrequency part of the signal could be further decomposed. As shown in Table 4, considering that wavelet packet analysis has the advantages of multilayer decomposition of signal details and scale information, the following wavelet packet energy feature extraction was conducted for the AE signal 

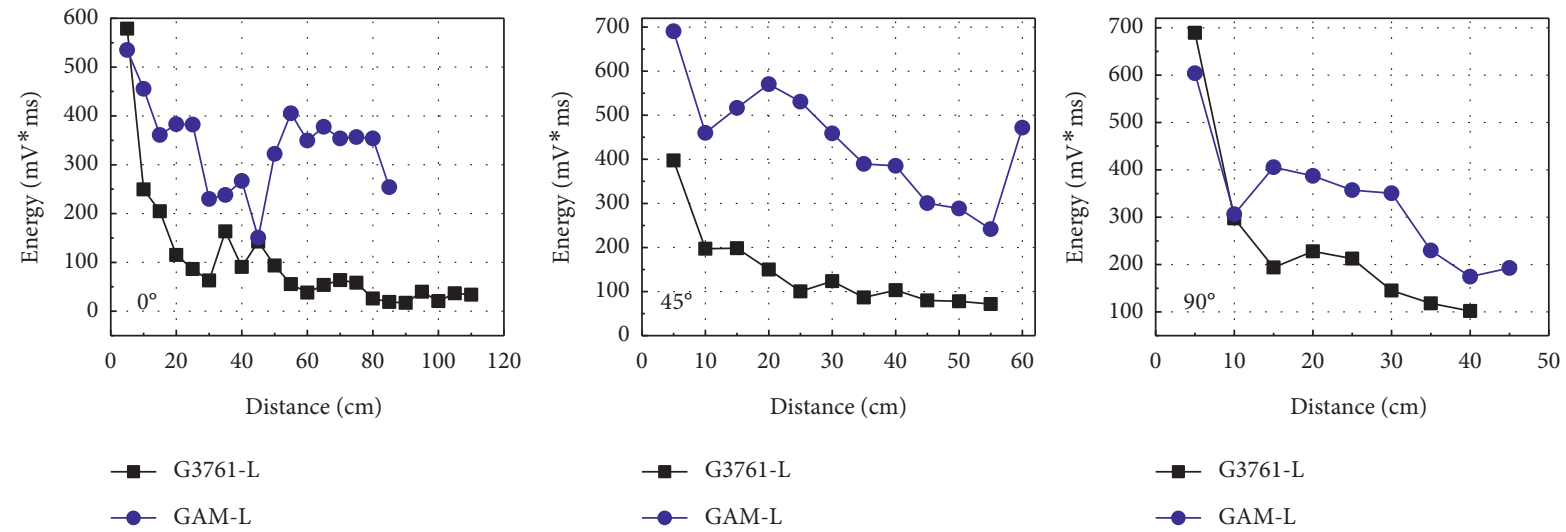

FIgure 6: The attenuation curves of the AE Energy in different directions for G3761-L and GAM-L.

TABLE 4: The measuring point positions of AE waveforms.

\begin{tabular}{|c|c|c|c|c|c|c|c|c|c|c|c|}
\hline \multirow{2}{*}{ Rock number (measuring point) $(\mathrm{cm})$} & \multirow{2}{*}{ G3768 } & \multirow{2}{*}{ G3561 } & \multirow{2}{*}{ TBG } & \multirow{2}{*}{ AAM } & \multirow{2}{*}{ GAM } & \multicolumn{3}{|c|}{ G3761-L } & \multicolumn{3}{|c|}{ GAM-L } \\
\hline & & & & & & $0^{\circ}$ & $90^{\circ}$ & $45^{\circ}$ & $0^{\circ}$ & $90^{\circ}$ & $45^{\circ}$ \\
\hline M1 & 5 & 5 & 5 & 5 & 5 & 5 & 5 & 5 & 5 & 5 & 5 \\
\hline M2 & 70 & 70 & 70 & 70 & 50 & 55 & 20 & 30 & 40 & 25 & 30 \\
\hline M3 & 135 & 135 & 135 & 135 & 100 & 100 & 35 & 50 & 75 & 40 & 50 \\
\hline
\end{tabular}

waveform obtained at different measuring points in each group of rock samples to explore the local feature information of the AE signal waveform at different positions of rod-shaped and plate-shaped rocks.

Choosing a suitable wavelet base plays an important role in signal processing and analysis. Guo [37] introduced the effect of different wavelet bases in vibration signal processing in detail, which presents that the $\mathrm{db} 5, \mathrm{db} 7, \mathrm{db} 10, \mathrm{db} 13, \mathrm{db} 16$, bior2.6, bior3.9, coif4, sym7, and sym8 wavelet bases are more suitable for the shock feature extraction of vibration signals. Of this wavelet set, $\mathrm{db} 7$ was selected as the wavelet base for the wavelet packet analysis because of its Daubechies series wavelet set characteristics such as high-order vanishing moment, tight support, regularity, approximate symmetry, and orthogonality-and because of the similarities it shares with the rock $\mathrm{AE}$ signal. Its wavelet function is presented in Figure 10.

The sampling frequency is $3 \mathrm{MHz}$. According to the sampling theorem, its Nyquist frequency is $1500 \mathrm{kHz}$. The wavelet packet decomposition principle and algorithm were applied to decompose the signal to the 7 th layer (i.e., the scale is 7), which has 27 wavelet packets in total. Therefore, in the frequency domain, the original signal was decomposed into 128 subbands. The width of each band was $11.72 \mathrm{kHz}$. The frequency band range of each layer reconstructed after the decomposition of the original signal is presented in Table 5.

As can be seen from the table, the original signal is expressed as

$$
S=S_{7,0}+S_{7,1}+S_{7,2}+\cdots+S_{7,127}
$$

where $S_{7,0}$ is the low-frequency part of the decomposed signal; the other variables represent the decomposition of the high-frequency part of the signal. Assuming that the corresponding energy of $S_{7, j}(j=0,1,2, \cdots, 127)$ is $E_{7, j}(j=0,1,2, \cdots, 127)$, then the energy characterization of the original $\mathrm{AE}$ signal decomposition in each frequency band range can be obtained by formula (1).

Assuming that the total energy of the analyzed signal is $E_{0}$, then

$$
E_{0}=\sum_{j=0}^{127} E_{7, j}
$$

The ratio of the energy of each frequency band to the total energy of the analyzed signal is

$$
E_{j}=\frac{E_{7, j}}{E_{0}} \times 100 \% \text {. }
$$

In the formula, $j=0,1,2, \ldots, 2^{7}-1$.

From Equation (1), the energy changes of the corresponding AE signals in different frequency bands after the original signal decomposition were calculated so the energy distribution characteristics of the elastic wave in different frequency bands could be found [38]. According to Table 4, the main frequency range of the AE signal waveform of each measuring point was $0-300 \mathrm{kHz}$, indicating that the energy value must also be concentrated in this frequency range. Therefore, with MATLAB programming, the energy distribution of each subband in the frequency domain of $0-500 \mathrm{kHz}$ was obtained, as shown in Figures 11 and 12.

For rod-shaped rocks G3768, G3561, and TBG of the same lithology from different places of origin, the M1 measuring point was closest to the pulse excitation source. Therefore, the value of the M1 measuring point could effectively reflect the energy value of the real pulse. As can be 


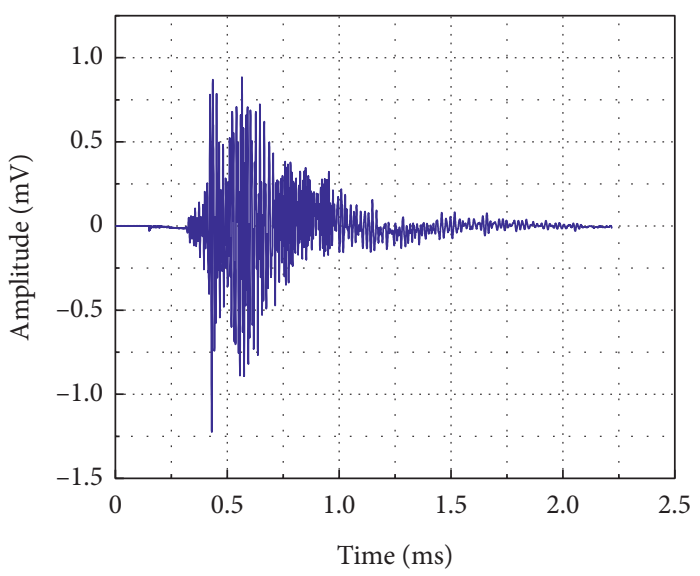

- G3768

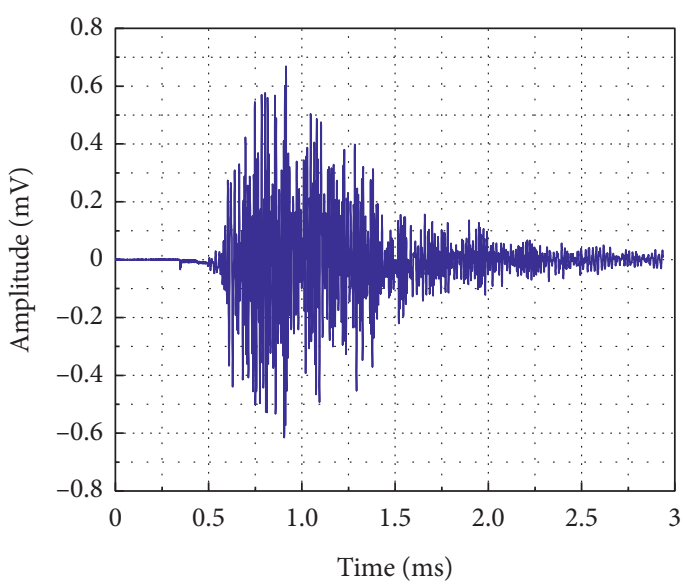

TBG

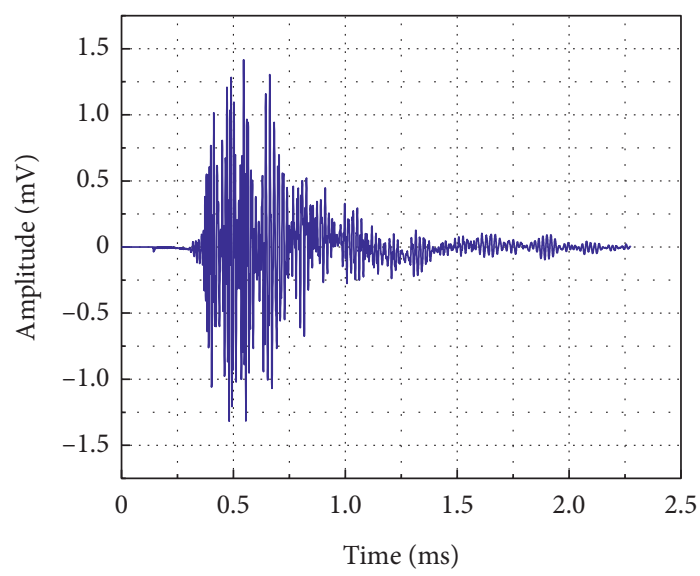

- G3561

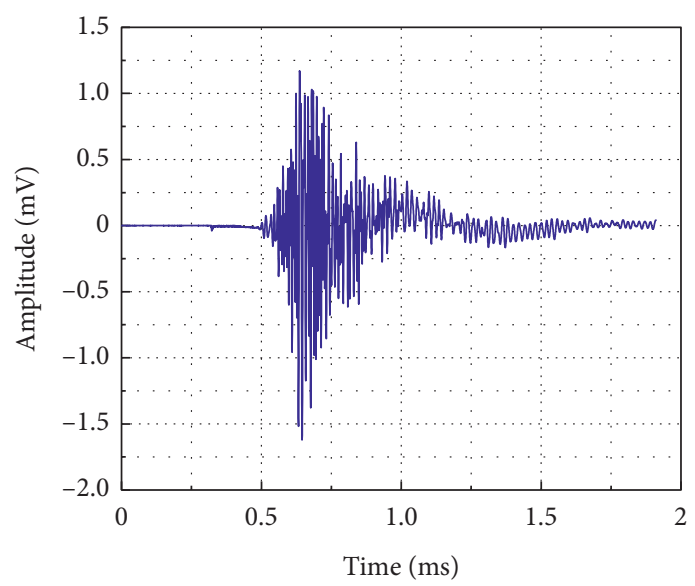

AAM

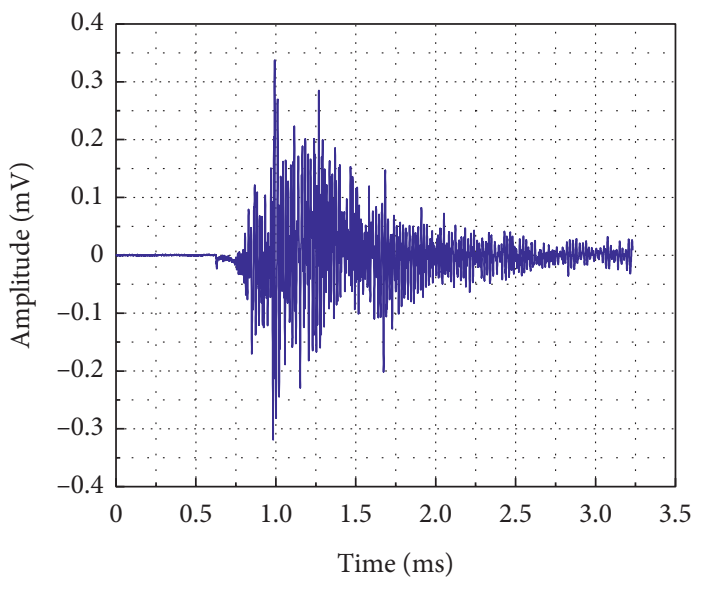

GAM

FIgURE 7: Time domain waveform of measuring point M2 of rod-shaped rock.

seen from Figure 11, the energy is widely distributed in the frequency domain. The value of energy is generally small, which was mainly concentrated in the range of $0-364.28 \mathrm{kHz}$. Combined with Formulas (5) and (6), it could be calculated that the main dominant energy of the three groups of granite was concentrated in the frequency band of $71.31-129.91 \mathrm{kHz}$, which correspondingly accounted for $64.6 \%, 56.05 \%$, and $58.28 \%$ of the total energy. About $23.26 \%$ of the energy in G3561 was concentrated in the frequency band of $235.38-352.56 \mathrm{kHz}$, which is different 


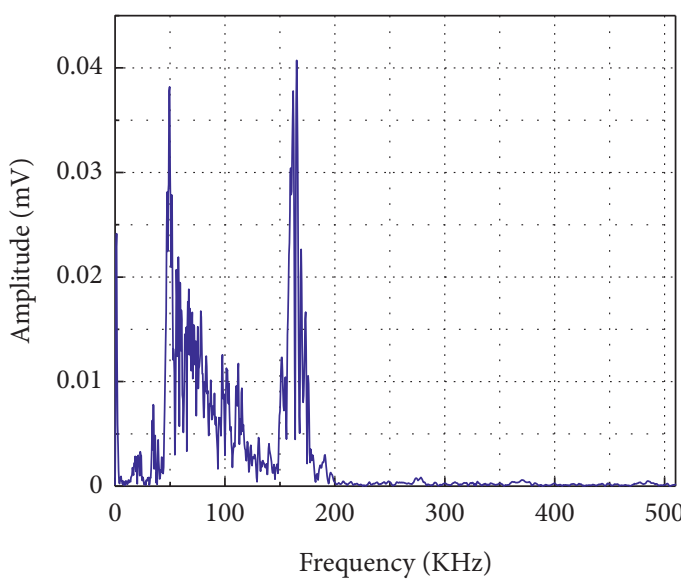

- G3768

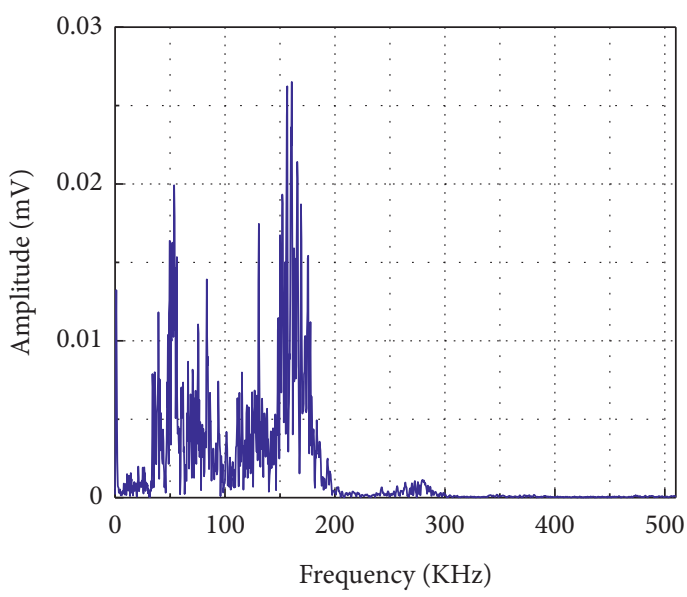

- TBG

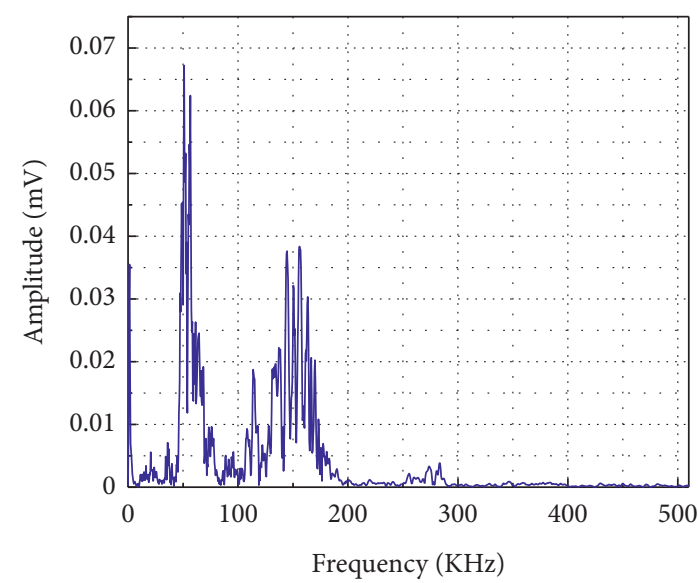

- G356

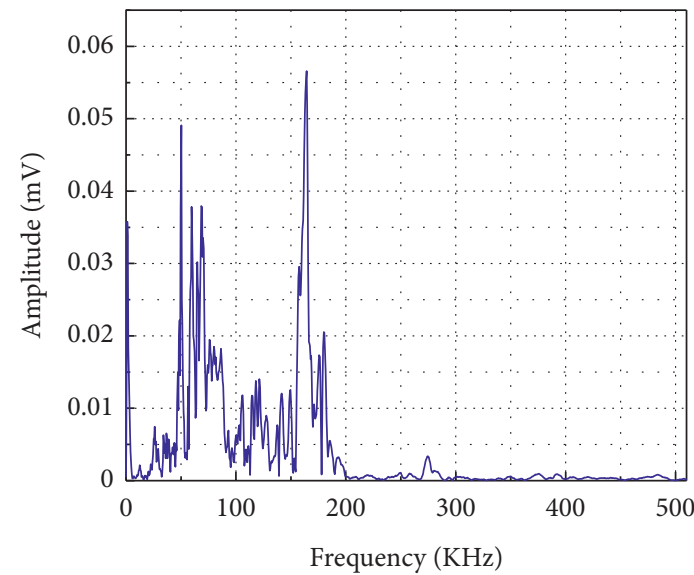

- AAM

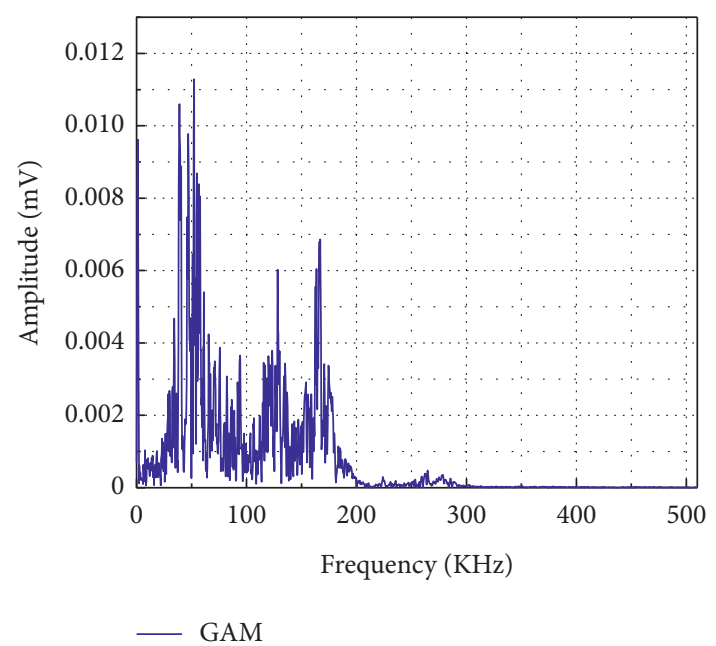

Figure 8: The spectrogram of measuring point M2 of rod-shaped rock.

from other samples of the same lithology. With the increase of the propagation distance of the elastic wave, its energy exhibited the characteristics of rapid attenuation. The dominant energy distribution frequency bands of the three rod-shaped rock materials at the M2 measuring point expanded from the initial $71.31-129.91 \mathrm{kHz}$ to $0-176.78 \mathrm{kHz}$, and the energy percentages were $89.87 \%, 94.07 \%$, and $86.58 \%$, respectively. In the high-frequency band of $282.25-317.41 \mathrm{kHz}$, there was, respectively, $10 \%$ and $12.69 \%$ energy concentration for G3768 and TBG. When the elastic wave propagated to the end of the rod (M3), the energy of each group of samples was relatively concentrated and 

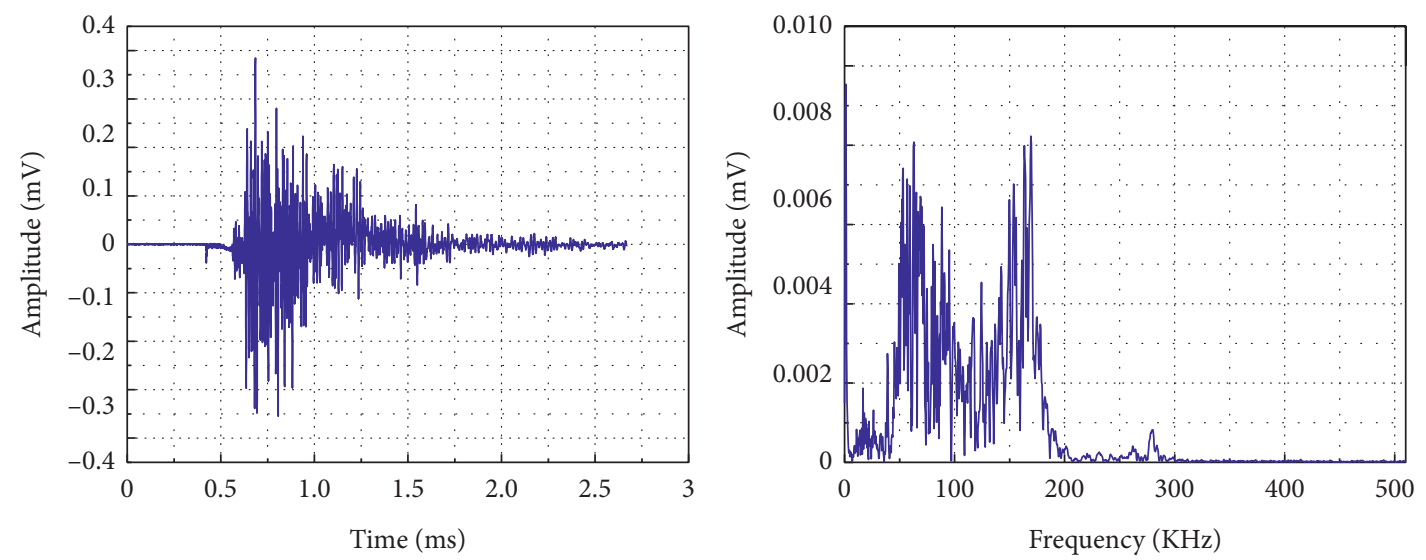

- G3761-L $\left(0^{\circ}\right)$

- G3761-L $\left(0^{\circ}\right)$
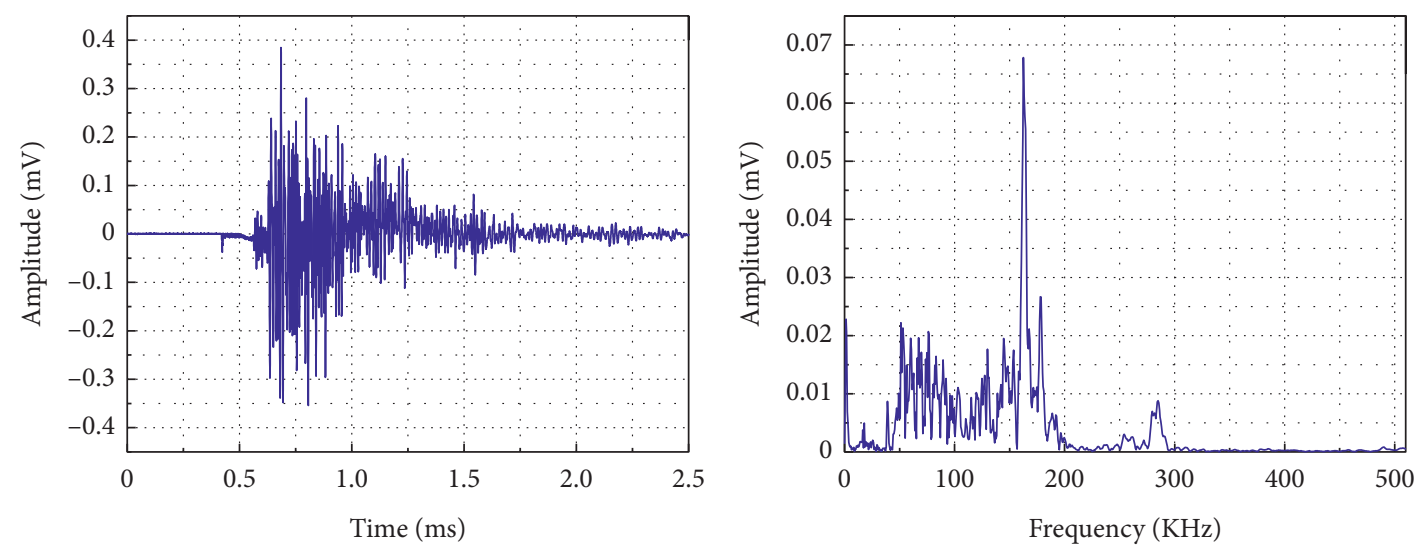

$-\mathrm{G} 3761-\mathrm{L}\left(45^{\circ}\right)$

- G3761-L $\left(45^{\circ}\right)$
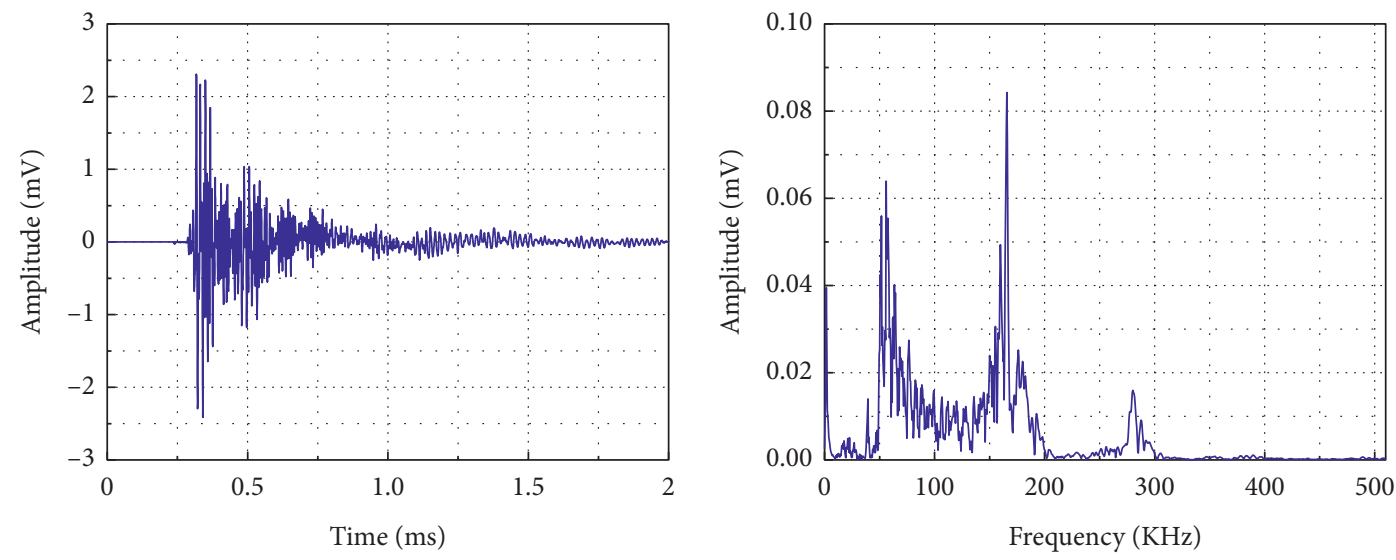

- G3761-L $\left(90^{\circ}\right)$

- $\mathrm{G} 3761-\mathrm{L}\left(90^{\circ}\right)$

(a)

Figure 9: Continued. 

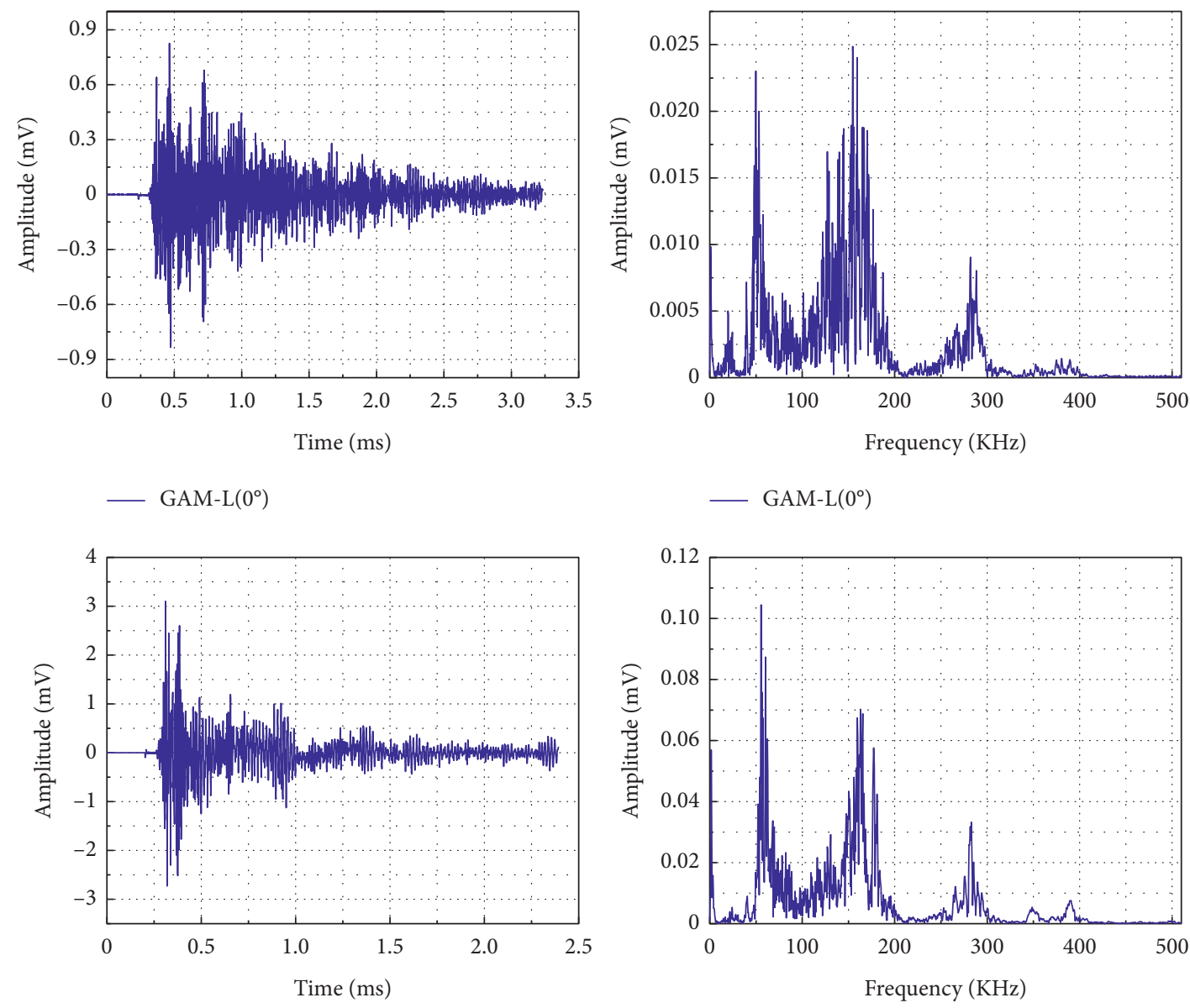

- GAM-L $\left(45^{\circ}\right)$
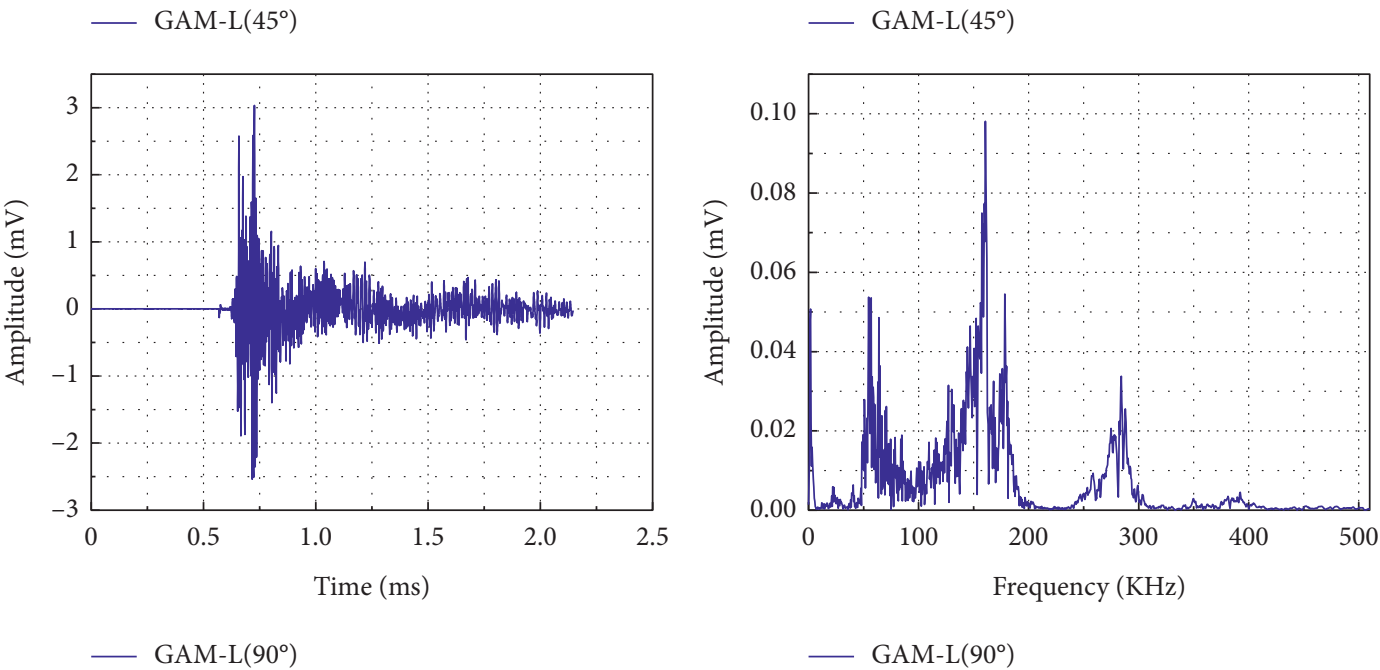

(b)

FIgURE 9: The time waveform and spectrogram of measuring point M2 of pate-shaped rock.

mainly distributed within $0-106.47 \mathrm{kHz}$ at the percentages of $92.11 \%, 90.22 \%$, and $91.88 \%$, respectively. By comparing the three groups of rod-shaped rocks with the same lithology, it can be seen that the energy attenuation was the fastest in TBG, and the dominant energy value was the lowest at the M3 measuring point. For G3768, the energy attenuation was the slowest. Only the distribution rule of the dominant energy value at the M2 and M3 measuring points changed, whereas the maximum energy value hardly changed. The reason may be that the internal structure or component density of G3768 was better, and the energy was relatively maintained rather than rapidly attenuated with the elastic wave propagation. For AAM artificial marble, its main dominant energy also exhibited the same change trend as 

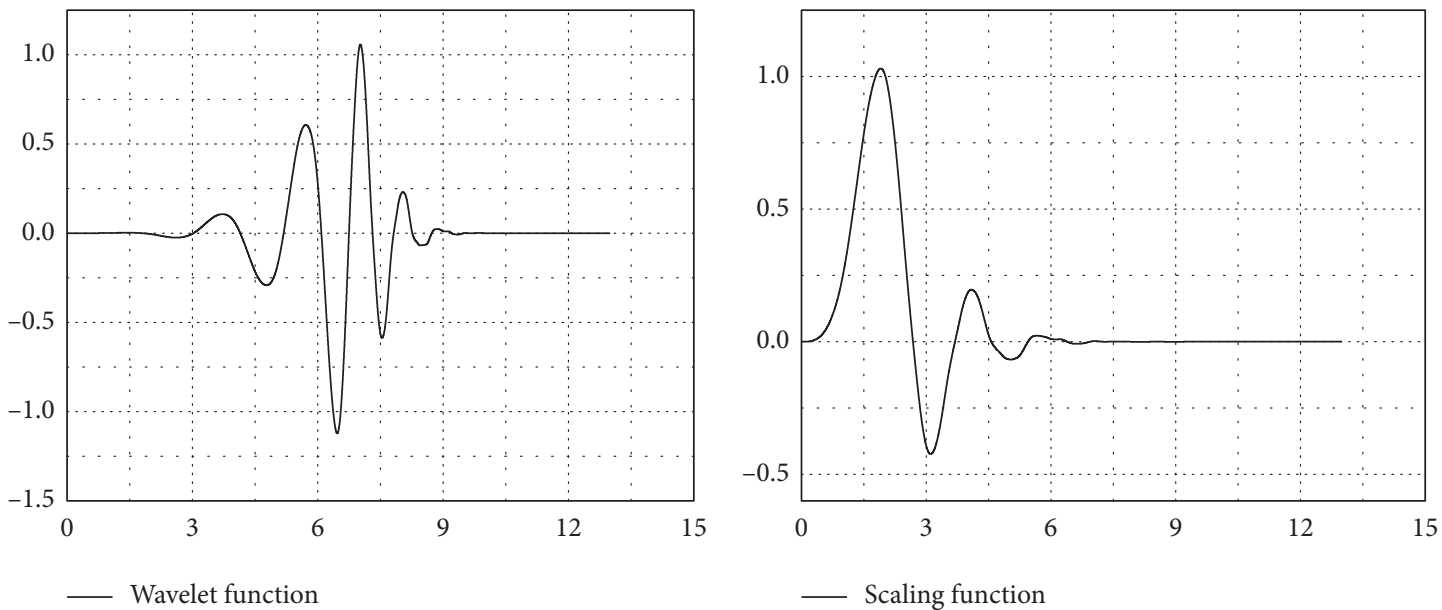

Figure 10: Wavelet function and scaling function for $\mathrm{db} 7$.

TABle 5: The frequency band range of reconstructed signal by wavelet packet decomposition.

\begin{tabular}{|c|c|c|c|c|c|c|}
\hline Layer & $S(i, 0)$ & $S(i, 1)$ & $S(i, 2)$ & $\ldots$ & $S(i, j-1)$ & $S(i, j)$ \\
\hline 1 & $0-750$ & - & - & - & - & $750-1500$ \\
\hline 2 & $0-375$ & $375-750$ & $750-1125$ & - & - & $1125-1500$ \\
\hline 3 & $0-187.5$ & $187.5-375$ & $375-562.5$ & $\ldots$ & $1125-1312.5$ & $1312.5-1500$ \\
\hline 4 & $0-93.75$ & $93.75-187.5$ & $187.5-281.25$ & $\ldots$ & $1312.5-1406.25$ & $1406.25-1500$ \\
\hline 5 & $0-46.875$ & $46.875-93.75$ & $93.75-140.625$ & $\ldots$ & $1406.25-1453.125$ & $1453.125-1500$ \\
\hline 6 & $0-23.4375$ & $23.4375-46.875$ & $46.875-70.3125$ & $\ldots$ & $1453.125-1476.5625$ & $1476.5625-1500$ \\
\hline 7 & $0-11.71875$ & $11.71875-23.4375$ & $23.4375-35.15625$ & $\ldots$ & $1476.5625-1488.28125$ & $1488.28125-1500$ \\
\hline
\end{tabular}

$\mathrm{S}(i, j)$ represents the reconstruction signal of the $\mathrm{j}$-th wavelet packet decomposition coefficient in the $\mathrm{i}$-th layer, $i=1,2,3,4 ; j=0,1,2, \ldots 2^{\mathrm{i}}-1$.
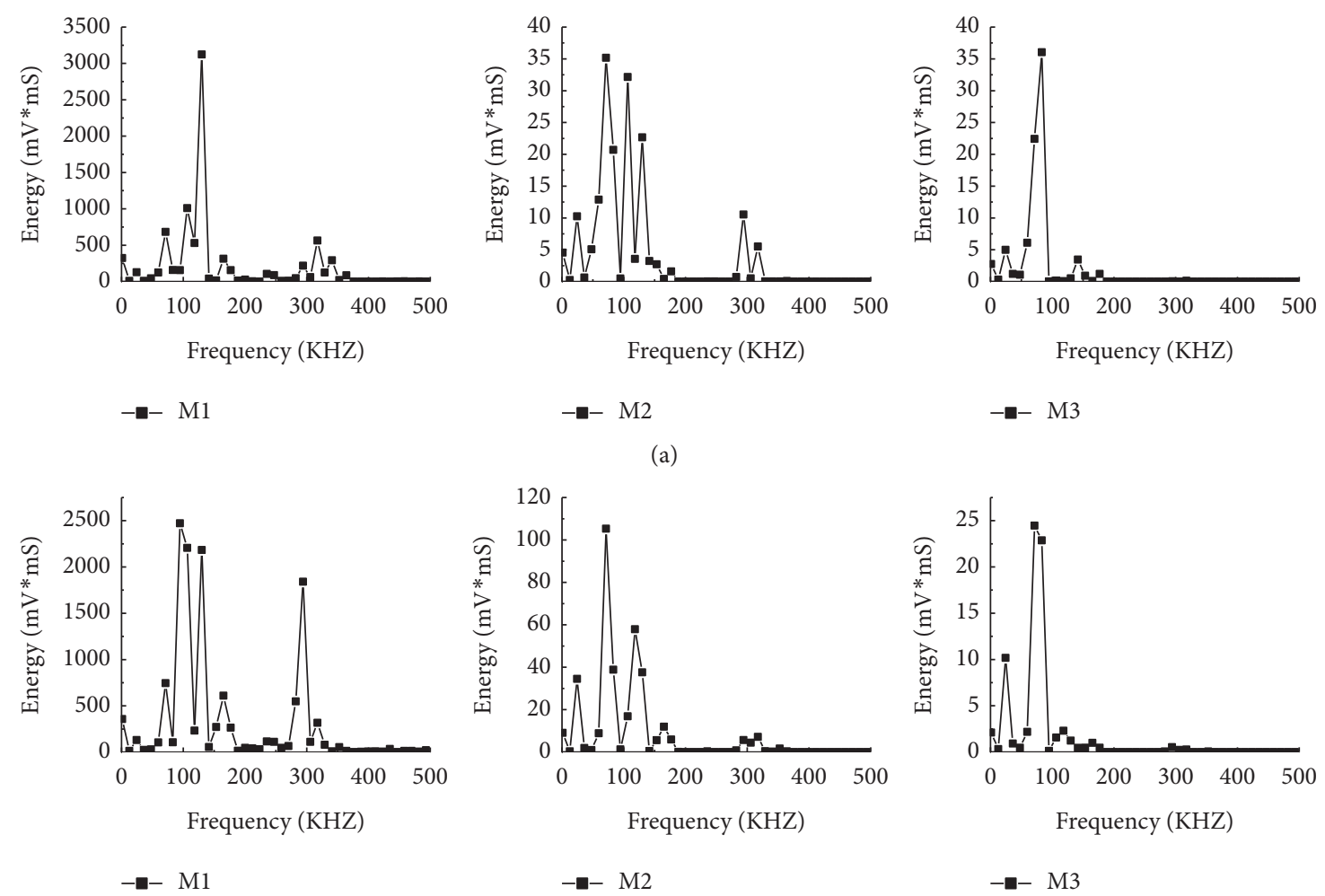

(b)

Figure 11: Continued. 

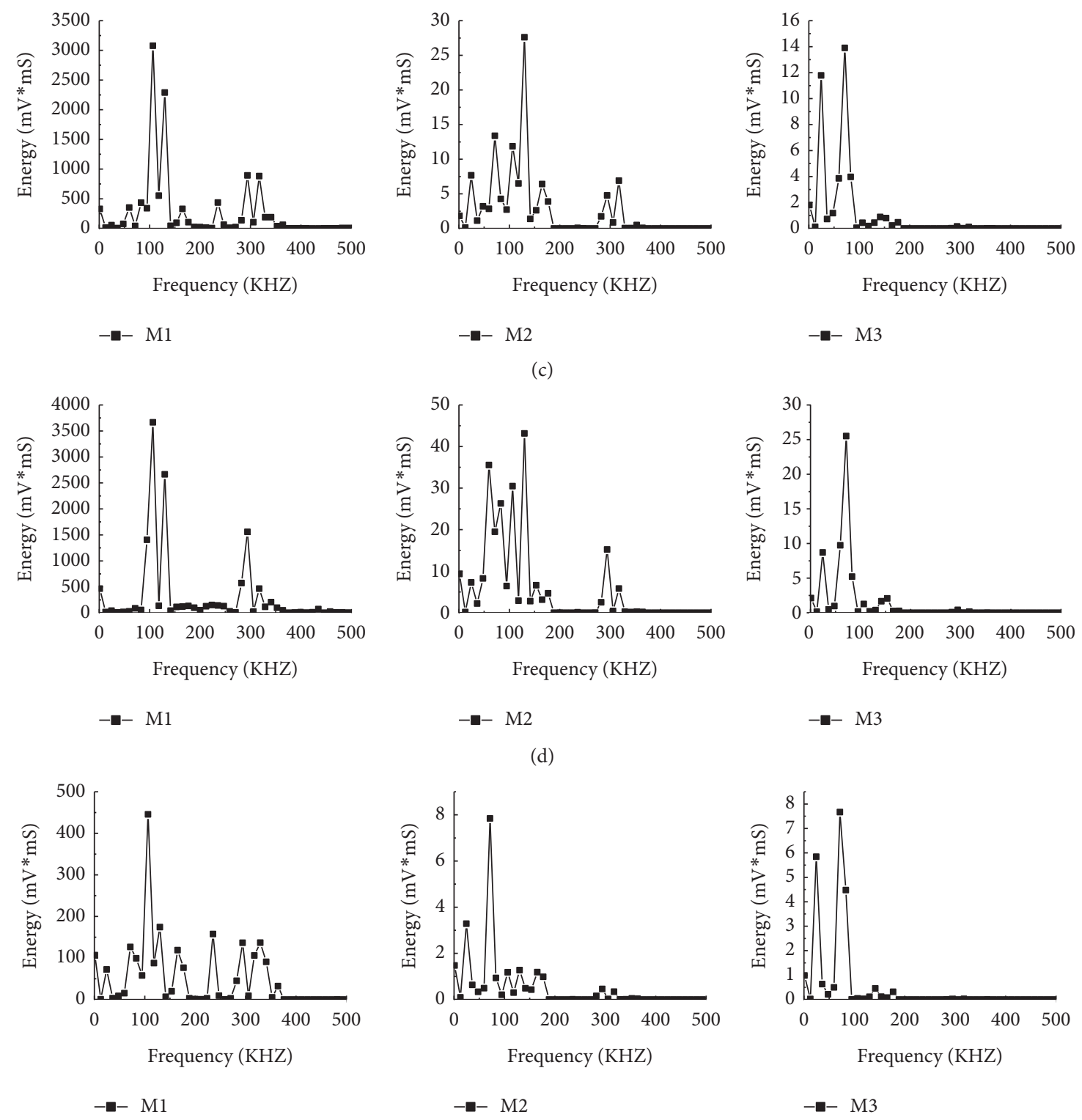

(e)

FIGURE 11: The energy distribution of acoustic emission signal frequency band of rod-shaped rock. (a) G3768. (b) G3561. (c) TBG. (d) AAM. (e) GAM.

granite. From Figure 11, it can be observed that the energy of the original pulse signal is concentrated in the range of $94.75-165.06 \mathrm{kHz}$, and $21.85 \%$ of the energy existed in the frequency band of $282.25-352.56 \mathrm{kHz}$. For GAM marble, the main dominant energy distribution of the initial signal was very wide and was distributed in the frequency band of $0-364.28 \mathrm{kHz}$. Among them, the dominant energy was distributed within the $106.47-129.91 \mathrm{kHz}$ range, accounting for $32.13 \%$ of the total energy. Similar attenuation characteristics as granite were presented with the increase of elastic wave propagation distance. In general, for GAM, the excitation energy of the AE signal generated by pulse excitation was the weakest, and the attenuation was the fastest with the increase of distance. The initial excitation energy of the three groups of granite was partially concentrated in the frequency band of $235.38-352.56 \mathrm{kHz}$, of which the performance of G3561 was the most obvious.

The pulse AE signal was very complex for 2 groups of the plate-shaped rocks (Figure 12). Therefore, the initial energy of the M1 measuring point in each direction was also quite different. In the direction of $0^{\circ}$, the dominant energy of the original pulse signal in G3761-L was concentrated in the frequency band of $0-176.78 \mathrm{kHz}$, which accounted for $89.04 \%$ of the total energy. Meanwhile, about $6.28 \%$ of the energy was distributed in the frequency band of $293.97-329.13 \mathrm{kHz}$. The same law was also shown in GAM$\mathrm{L}$, but the main dominant frequency in GAM-L was relatively concentrated in the short frequency band of $106.47-176.78 \mathrm{kHz}$, which accounted for $63.57 \%$ of the total energy. With the spread of the elastic wave, the energy in 

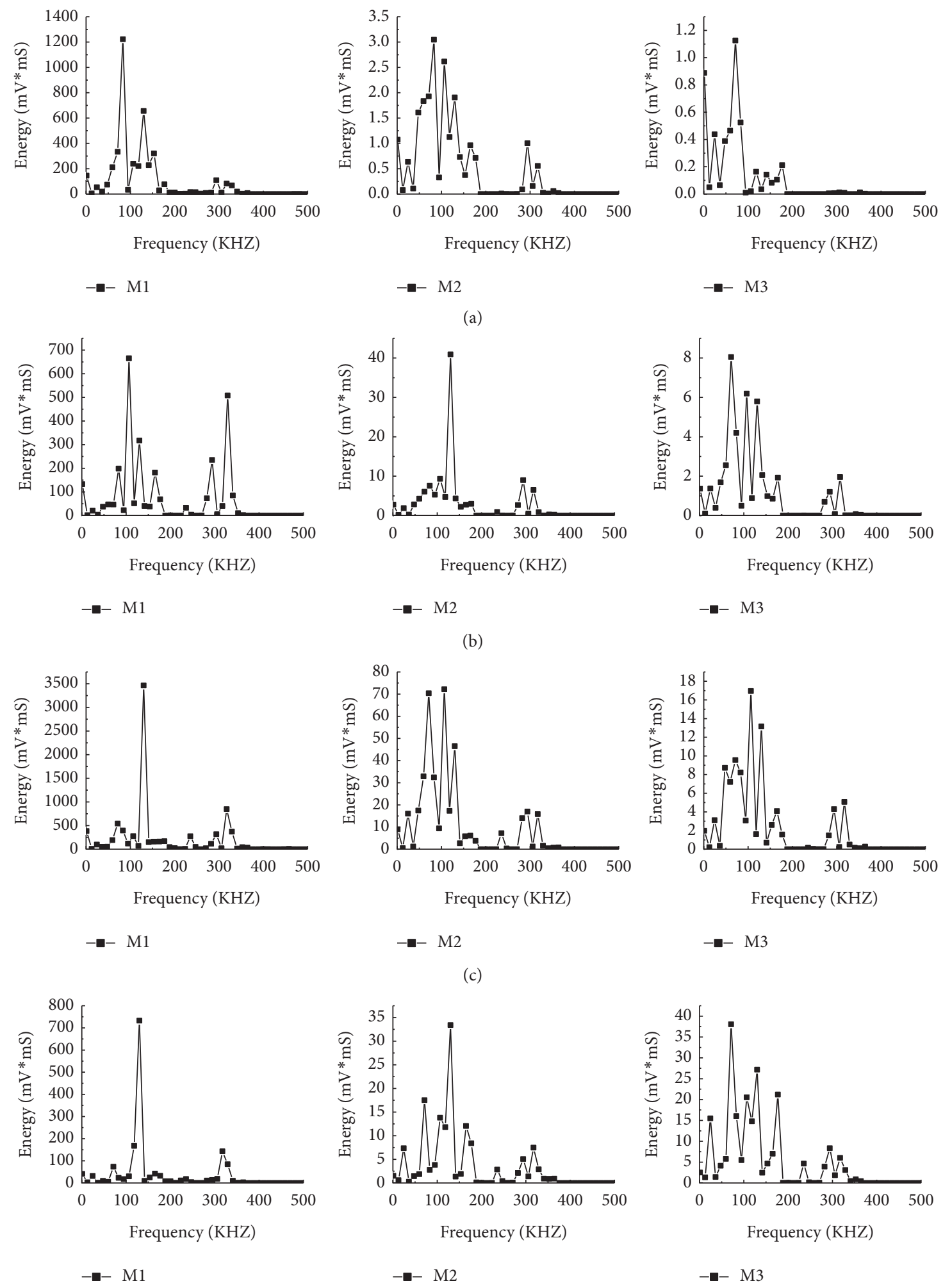

(d)

FIgURE 12: Continued. 

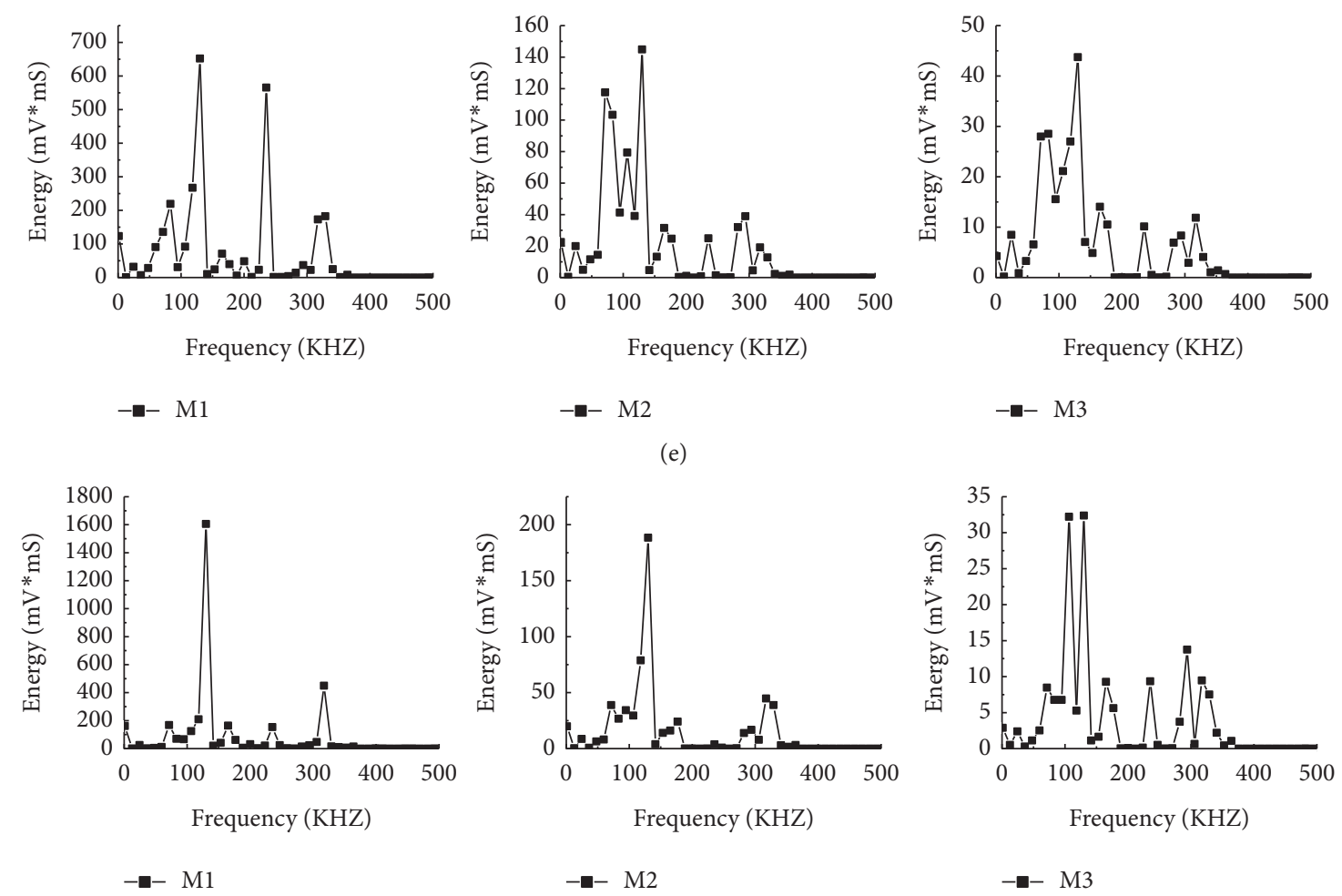

(f)

FIGURE 12: The energy distribution of acoustic emission signal frequency band of plate-shaped rock. (a) G3761-L (00). (b) G3761-L (450). (c) G3761-L (900). (d) GAM-L (00). (e) GAM-L (450). (f) GAM-L (900).

G3761-L showed a trend of attenuation, and the energy in the M2 measuring point was still distributed in the frequency band of $0-176.78 \mathrm{kHz}$. The energy distribution at the M3 measuring point was relatively concentrated and was located in the frequency band of $0-106.47 \mathrm{kHz}$, accounting for $83.40 \%$ of the total energy. The energy at the measuring point M3 of GAM-L was more extensive in the frequency domain, and the energy value changed dramatically, demonstrating the abnormal phenomenon that the main dominant energy increased. The frequency range of this measuring point was $0-188.5 \mathrm{kHz}$, accounting for $85.89 \%$ of the total energy. There was also residual energy concentrated in the frequency band of $293.97-329.13 \mathrm{kHz}$. The AE signal at M3 was superposed by the boundary reflection wave, and the energy was enhanced because of the high homogeneity and good ductility of GAM-L. For G3761-L, the dominant energy of the elastic wave almost dissipated at the M3 measuring point. In the direction of $45^{\circ}$, the dominant energy band of the original signal in G3761-L was distributed within $0-176.78 \mathrm{kHz}$ and $282.25-352.56 \mathrm{kHz}$, respectively, accounting for $64.15 \%$ and $32.78 \%$ of the total energy. Moreover, it can be observed that the distribution of the dominant energy band was from distribution to concentration, which was distributed in the frequency band of $71.31-176.78 \mathrm{kHz}$ at $\mathrm{M} 2$. With the increase of distance, the energy frequency band of the M3 measuring point near the edge of the plate was spread again, and it was restored to the energy frequency band range of the initial signal. However, the energy value was attenuated to a very small value at this moment. The energies of GAM-L in the measuring points $\mathrm{M} 1, \mathrm{M} 2$, and M3 were all distributed in the frequency band of $0-364.28 \mathrm{kHz}$. In the direction of $90^{\circ}$, the primary dominant energy frequency bands of the two plate-shaped rocks were concentrated in $94.75-188.5 \mathrm{kHz}$. The difference is that the energy distribution of GAM-L was still concentrated, and the energy variation was much smaller than G3761-L at the M2 measuring point. In general, the energy frequency band of the two plate-shaped rocks with different lithologies was the same as that of the rod-shape rock, which is mainly distributed in the range of $0-364.28 \mathrm{kHz}$. Moreover, they also exhibited the characteristics that the main dominant energy was distributed in the range of $0-176.78 \mathrm{kHz}$, and the residual energy was distributed in the range of $282.25-352.56 \mathrm{kHz}$.

\section{Discussion}

The purpose of this work was to study the propagation characteristics of elastic wave in lithological rock materials. Through the above research and analysis, a preliminary understanding was obtained. Based on the deep wavelet packet analysis of amplitude, energy characteristic parameters, and AE waveform, the frequency band characteristics of the local energy distribution of elastic wave with its propagation were summarized. However, its propagation characteristics are difficult to be regularly grasped because the elastic wave itself is extremely complex. Furthermore, AE technology is mostly used in the damage detection and 
defect location of metal or related materials with good compactness, ductility, and within the same medium. There are many uncertain interference factors in the experiments. In some aspects, the analysis of this paper only stays at the level of the apparent phenomenon, and there are still many deficiencies and areas worthy of improvement. For instance, the density, wave velocity, and wave impedance of the rodshaped rock samples should be tested, and the microstructure imaging experiments of the rock samples should be conducted. The quality factor $Q$ of different rock samples should be calculated. Moreover, the correlation between the quality factor and wave impedance should be studied, and the influence of different microcompositions of rod-shaped rocks on elastic wave attenuation should be deeply analyzed. Based on the modal AE theory, the influence of Lamb wave in plate-shaped rocks should be studied, and the propagation model of two-dimensional AE should be constructed. The Gabor wavelet should be introduced to analyze the AE signal by time-frequency analysis. The influence of different wavelets based on the propagation effect of $\mathrm{AE}$ will be compared and analyzed, and the time of the same mode of the $\mathrm{AE}$ wave arriving at the sensor will be determined to further optimize the plane location algorithm. However, the research in this work is still useful for studying large-scale rock samples in the future and provides effective research methods and ideas for the study of elastic wave propagation characteristics of different rock materials and composite materials.

\section{Conclusions}

In this work, the characteristic parameter analysis and waveform analysis of the AE signals obtained from different experimental schemes in 5 groups of rod-shaped rocks and 2 groups of plate-shaped rocks were carried out. The conclusions are as follows:

(1) The amplitude and energy of the rod-shaped rocks gradually attenuated with the increase of distance. The amplitude can directly reflect the intensity of the $\mathrm{AE}$ counts at different measuring areas. In the process of elastic wave propagation of the rod-shaped rock, the $\mathrm{P}$-wave preceded the S-wave and changed violently. The elastic wave of marble attenuated faster, and the elastic wave of the three kinds of granite decayed attenuated closely. Among them, the elastic wave of TBG exhibited the fastest attenuation.

(2) In flat plate-shaped rocks, the amplitude exhibited an approximate exponential attenuation characteristic with the increase of the propagation distance. Granite exhibited a stronger elastic wave attenuation in the $0^{\circ}$ direction than the marble, and the marble presented fast attenuations in the $45^{\circ}$ and $90^{\circ}$ directions. The energy change of marble was dramatic, and the energy value in the interval of $45-55 \mathrm{~cm}$ at the direction of $0^{\circ}$ showed the abnormal step phenomenon. The energy value of the marble increased after $55 \mathrm{~cm}$ in the $45^{\circ}$ direction. The energy value of granite from the back to the end of the plate was almost maintained and tended to be stable at 20-50 mV ms.

(3) The frequency range of the energy distribution of samples in this work was within $0-364.28 \mathrm{kHz}$. With the increase of distance, the main dominant energy distribution of the 5 groups of rod-shaped rocks in the frequency range was characterized by distribution to relative concentration and rapid energy attenuation. The main dominant energy distribution of the 2 groups of plate-shaped rocks was distributed in the range of $0-176.78 \mathrm{kHz}$. All rod-shaped rocks and plate-shaped rocks exhibited the characteristics of residual energy distribution in the frequency band of $282.25-352.56 \mathrm{kHz}$.

\section{Data Availability}

The data used to support the findings of this study are available from the corresponding author upon request.

\section{Conflicts of Interest}

The authors certify that they have no conflicts of interest.

\section{Acknowledgments}

This research was funded by the National Natural Science Foundation of China (51804161, 52074156, and 52004291), the Chinese Postdoctoral Science Foundation (2019M660861), and the State Key Laboratory Cultivation Base for Gas Geology and Gas Control (Henan Polytechnic University) (WS2020A04).

\section{References}

[1] J. T. Chen, J. H. Zhao, S. C. Zhang, Y. Zhang, F. Yang, and M. Li, "An experimental and analytical research on the evolution of mining cracks in deep floor rock mass," Pure and Applied Geophysics, vol. 177, no. 11, pp. 5325-5348, 2020.

[2] K. Wang and F. Du, "Coal-gas compound dynamic disasters in China: a review," Process Safety and Environmental Protection, vol. 133, pp. 1-17, 2020.

[3] C. Zhu, M. He, M. Karakus, X. Cui, and Z. Tao, "Investigating toppling failure mechanism of anti-dip layered slope due to excavation by physical modelling," Rock Mechanics and Rock Engineering, vol. 53, no. 11, pp. 5029-5050, 2020.

[4] X. Wang, C. Liu, S. Chen, L. Chen, K. Li, and N. Liu, "Impact of coal sector's de-capacity policy on coal price," Applied Energy, vol. 265, Article ID 114802, 2020.

[5] D. Liu, Z. Gu, R. Liang et al., "Impacts of pore-throat system on fractal characterization of tight sandstones," Geofluids, vol. 2020, no. 9, 17 pages, Article ID 4941501, 2020.

[6] J. Wang, Y. Zhang, Z. Qin, S. Song, and P. Lin, "Analysis method of water inrush for tunnels with damaged waterresisting rock mass based on finite element method-smooth particle hydrodynamics coupling," Computers and Geotechnics, vol. 126, Article ID 103725, 2020.

[7] B. Chen, S. C. Zhang, Y. Y. Li, Z. K. Li, and H. J. Zhou, "Physical simulation study of crack propagation and instability information discrimination of rock-like materials with faults," Arabian Journal of Geosciences, vol. 13, p. 966, 2020. 
[8] F. Du, K. Wang, X. Zhang, C. Xin, and G. Wang, "Experimental study of coal-gas outburst: insights from coal-rock structure, gas pressure and adsorptivity," Natural Resources Research, vol. 29, no. 4, pp. 2481-2493, 2020.

[9] H. Y. Wang, J. Ma, G. D. Wang et al., "Research on AE source location of linear and plane rock mass," Shock and Vibration, vol. 2020, Article ID 8846582, 18 pages, 2020.

[10] V. A. Mansurov, "Prediction of rockbursts by analysis of induced seismicity data," International Journal of Rock Mechanics and Mining Sciences, vol. 38, no. 6, pp. 893-901, 2001.

[11] M. C. He, J. L. Miao, and J. L. Feng, "Rock burst process of limestone and its acoustic emission characteristics under truetriaxial unloading conditions," International Journal of Rock Mechanics and Mining Sciences, vol. 47, no. 2, pp. 286-298, 2010.

[12] F. Gong, J. Yan, X. Li, and S. Luo, "A peak-strength strain energy storage index for rock burst proneness of rock materials," International Journal of Rock Mechanics and Mining Sciences, vol. 117, pp. 76-89, 2019.

[13] F. Du and K. Wang, "Unstable failure of gas-bearing coal-rock combination bodies: insights from physical experiments and numerical simulations," Process Safety and Environmental Protection, vol. 129, pp. 264-279, 2019.

[14] S. D. Butt, C. Mukherjee, and G. Lebans, "Evaluation of acoustic attenuation as an indicator of roof stability in advancing headings," International Journal of Rock Mechanics and Mining Sciences, vol. 37, no. 7, pp. 1123-1131, 2000.

[15] M. Cai, H. Morioka, P. K. Kaiser et al., "Back-analysis of rock mass strength parameters using ae monitoring data," International Journal of Rock Mechanics and Mining Sciences, vol. 44, no. 4, pp. 538-549, 2007.

[16] D. P. Jansen, S. R. Carlson, R. P. Young, and D. A. Hutchins, "Ultrasonic imaging and acoustic emission monitoring of thermally induced microcracks in Lac du Bonnet granite," Journal of Geophysical Research: Solid Earth, vol. 98, no. B12, pp. 22231-22243, 1993.

[17] U. Bismayer, "Early warning signs for mining accidents: detecting crackling noise," American Mineralogist, vol. 102, no. 1, pp. 3-4, 2017

[18] X. Kong, E. Wang, S. Li, H. Lin, P. Xiao, and K. Zhang, "Fractals and chaos characteristics of acoustic emission energy about gas-bearing coal during loaded failure," Fractals, vol. 27, no. 5, Article ID 195072, 2019.

[19] F. Du, K. Wang, G. Wang, Y. Jiang, C. Xin, and X. Zhang, "Investigation of the acoustic emission characteristics during deformation and failure of gas-bearing coal-rock combined bodies," Journal of Loss Prevention in the Process Industries, vol. 55, pp. 253-266, 2018.

[20] R. P. Young, D. A. Hutchins, S. Talebi et al., "Laboratory and field investigations of rockburst phenomena using concurrent geotomographic imaging and acoustic emission/microseismic techniques," Seismicity in Mines, vol. 129, no. 3-4, pp. 647-659, 1989.

[21] X. Jansen, H. Xu, M. He, and F. Zhang, "Experimental investigation of the occurrence of rockburst in a rock specimen through infrared thermography and acoustic emission," International Journal of Rock Mechanics and Mining Sciences, vol. 93, pp. 250-259, 2017.

[22] R. E. Goodman and E. Richard, "Subaudible noise during compression of rocks," Geological Society of America Bulletin, vol. 74, no. 4, pp. 487-490, 1963.

[23] M. Cai, P. K. Kaiser, H. Morioka et al., "FLAC/PFC coupled numerical simulation of $\mathrm{AE}$ in large-scale underground excavations," International Journal of Rock Mechanics and Mining Sciences, vol. 44, no. 4, pp. 550-564, 2007.

[24] V. Saltas, F. Vallianatos, D. Triantis, T. Koumoudeli, and I. Stavrakas, "Non-extensive statistical analysis of acoustic emissions series recorded during the uniaxial compression of brittle rocks," Physica A: Statistical Mechanics and Its Applications, vol. 528, Article ID 121498, 2019.

[25] V. Saltas, I. Fitilis, and F. Vallianatos, "A combined complex electrical impedance and acoustic emission study in limestone samples under uniaxial loading," Tectonophysics, vol. 637, pp. 198-206, 2014.

[26] G. Qi, "Wavelet-based AE characterization of composite materials," NDT \& E International, vol. 33, no. 3, pp. 133-144, 2000.

[27] G. Manthei, J. Eisenblätter, and T. Dahm, "Moment tensor evaluation of acoustic emission sources in salt rock," Construction and Building Materials, vol. 15, no. 5-6, pp. 297-309, 2001.

[28] H. Jeong and Y.-S. Jang, "Wavelet analysis of plate wave propagation in composite laminates," Composite Structures, vol. 49, no. 4, pp. 443-450, 2000.

[29] S.-H. Chang and C.-I. Lee, "Estimation of cracking and damage mechanisms in rock under triaxial compression by moment tensor analysis of acoustic emission," International Journal of Rock Mechanics and Mining Sciences, vol. 41, no. 7, pp. 1069-1086, 2004.

[30] T. Hirata, T. Satoh, and K. Ito, "Fractal structure of spatial distribution of microfracturing in rock," Geophysical Journal International, vol. 90, no. 2, pp. 369-374, 1987.

[31] X. Lei, K. Masuda, O. Nishizawa et al., "Detailed analysis of acoustic emission activity during catastrophic fracture of faults in rock," Journal of Structural Geology, vol. 26, no. 2, pp. 247-258, 2004.

[32] J. Jouniaux, J. Pei, J. Liu et al., "Investigation on acoustic emission behavior and its time-space evolution mechanism in failure process of coal-rock combined body," Chinese Journal of Rock Mechanics and Engineering, vol. 30, pp. 1564-1570, 2011.

[33] E. Townend, B. D. Thompson, P. M. Benson, PG. Meredith, P. Baud, and R. P. Young, "Imaging compaction band propagation in Diemelstadt sandstone using acoustic emission locations," Geophysical Research Letters, vol. 35, no. 15, pp. 189-193, 2008.

[34] M. Naderloo, M. Moosavi, and M. Ahmadi, "Using acoustic emission technique to monitor damage progress around joints in brittle materials," Theoretical and Applied Fracture Mechanics, vol. 104, Article ID 102368, 2019.

[35] GB/T, Unified Number of Natural Stone, China Standards Press, Beijing, China, 2009.

[36] G. Shen, Acoustic Emission Detection Technology and Application, Science Press, Beijing, China, 2015.

[37] Y. Guo, Research on Wavelet Base Selection for Vibration Signal Processing, Hefei University of Technology, Hefei, China, 2003.

[38] F. Xu, E. Wang, and D. Song, "Long-range correlation and multifractal distribution of acoustic emission of coal-rock," Rock and Soil Mechanics, vol. 32, no. 7, pp. 2111-2116, 2011. 